\title{
High-throughput molecular analysis in lung cancer: insights into biology and potential clinical applications
}

\author{
S. Ocak*, M.L. Sos" ${ }^{\#}$ R.K. Thomas ${ }^{\#, q_{,}+}$and P.P. Massion*, ${ }^{\S}$
}

ABSTRACT: During the last decade, high-throughput technologies including genomic, epigenomic, transcriptomic and proteomic have been applied to further our understanding of the molecular pathogenesis of this heterogeneous disease, and to develop strategies that aim to improve the management of patients with lung cancer. Ultimately, these approaches should lead to sensitive, specific and noninvasive methods for early diagnosis, and facilitate the prediction of response to therapy and outcome, as well as the identification of potential novel therapeutic targets.

Genomic studies were the first to move this field forward by providing novel insights into the molecular biology of lung cancer and by generating candidate biomarkers of disease progression. Lung carcinogenesis is driven by genetic and epigenetic alterations that cause aberrant gene function; however, the challenge remains to pinpoint the key regulatory control mechanisms and to distinguish driver from passenger alterations that may have a small but additive effect on cancer development.

Epigenetic regulation by DNA methylation and histone modifications modulate chromatin structure and, in turn, either activate or silence gene expression. Proteomic approaches critically complement these molecular studies, as the phenotype of a cancer cell is determined by proteins and cannot be predicted by genomics or transcriptomics alone.

The present article focuses on the technological platforms available and some proposed clinical applications. We illustrate herein how the "-omics" have revolutionised our approach to lung cancer biology and hold promise for personalised management of lung cancer.

KEYWORDS: Biomarkers, high throughput, lung cancer, -omics, translational

ung cancer is the leading cause of cancerrelated mortality worldwide among both males and females, with $>1$ million deaths annually [1]. Despite recent advances made in diagnosis and treatment strategies, nonsmall cell lung cancer (NSCLC) prognosis remains poor, with a 5 -yr overall survival of $15 \%$ [1]. More than $60 \%$ of patients are diagnosed with advanced or metastatic disease, mainly due to a lack of early diagnosis tools, and are subsequently not eligible for surgical resection. Although surgery offers the best chance for a cure, 5-yr overall survival remains disappointing at 50\% [2]. Recent studies have shown that survival might be improved by platinum-based adjuvant chemotherapy [3, 4], but which patients might benefit from it is not clear. In recent years, some new methods have been developed for high-throughput molecular
AFFILIATIONS

*Division of Allergy, Pulmonary and Critical Care Medicine, Thoracic Oncology Center, Vanderbilt-Ingram Cancer Center,

${ }^{\S}$ Veterans Affairs Medical Center, Nashville, TN, USA.

\# Max Planck Institute for

Neurological Research with KlausJoachim-Zülch Laboratories of the Max Planck Society and the Medica Faculty of the University of Köln, "Dept of Internal Medicine and Center of Integrated Oncology KölnBonn, University of Köln, Köln, and ${ }^{+}$Chemical Genomics Center of the Max Planck Society, Dortmund, Germany.

CORRESPONDENCE P.P. Massion

Division of Allergy, Pulmonary and Critical Care Medicine

Vanderbilt-Ingram Cancer Center 2220 Pierce Avenue

Preston Research Building 640

Nashville

TN 37232-6838

USA

E-mail: pierre.massion@

vanderbilt.edu

Received:

March 152009

Accepted after revision:

April 032009
Previous articles in this series: No. 1: De Wever W, Stroobants S, Coden J, et al. Integrated PET/CT in the staging of nonsmall cell lung cancer: technical aspects and resection for lung cancer. Eur Respir J 2009; 33: 201-212. No. 2: Rami-Porta R, Tsuboi M. Sublobar resection for lung cancer. Eur Respir J 2009; 33: 426-435. No. 3: McWilliams A, Lam B, Sutedja T. Early proximal lung cancer diagnosis and treatment. Eur Respir J 2009; 33: 656-665. No. 4: Sculier J-P, Moro-Sibilot D. First- and second-line therapy for advanced nonsmall cell lung cancer. Eur Respir J 2009; 33: 916-930. No. 5: van Tilburg PMB, Stam H, Hoogsteden HC, et al. Pre-operative pulmonary evaluation of lung cancer patients: a review of the literature. Eur Respir J 2009; 33: 1206-1215. No. 6: Brambilla E, Gazdar A. Pathogenesis of lung cancer signalling pathways: roadmap for therapies. Eur Respir J 2009; 33: 1482-1497. No. 7: Horváth I, Lázár Z, Gyulai N. Kollai M, Losonczy G. Exhaled biomarkers in lung cancer. Eur Respir J 2009; 34: 261-275.
European Respiratory Journal Print ISSN 0903-1936 Online ISSN 1399-3003 
analysis of tumours and have provided markers as powerful tools for the development of innovative diagnostic and therapeutic strategies in cancer. Genomic studies have been pioneering in providing information on lung cancer molecular biology [5], followed by clear evidence that both genetic and epigenetic alterations are driving carcinogenesis. More recently, proteomic approaches were revealed to be crucial, as the phenotype of a cell is determined by proteins and cannot be predicted by genomics or transcriptomics alone. Indeed, expression levels of proteins are poorly correlated with those of messenger RNA [6], and proteins are commonly subject to post-translational modifications (e.g. phosphorylation, glycosylation) that may modify their functions. This article evaluates the four main categories of high-throughput molecular analysis (genomics, epigenomics, transcriptomics and proteomics) and summarises lessons learned in lung cancer biology and their upcoming new clinical applications.

\section{METHODOLOGICAL ASPECTS}

A summary of selected high-throughput methodologies is presented in table 1 .

\section{Genomics}

Genomics is the study of an organism's entire genome. The most important of the related technologies are high-throughput capillary sequencing, comparative genomic hybridisation (CGH) arrays and single-nucleotide polymorphism (SNP) arrays.

\section{Global genome sequencing}

Global genome sequencing has made major improvements from gel-based sequencing to automated reading of the TGCA oligonucleotides [7-9]. A better separation system, called capillary electrophoresis, allows DNA to be sorted inside capillary tubes instead of in a gel, which allows the automation of the DNA loading system, leading to an increase in throughput and higher speeds. The new sequencers do not use the old chain-termination paradigm; instead sequencingby-synthesis technology binds short fragments of DNA to small beads that are dropped into wells in a fibreoptic chip. The DNA adds another molecule to its chain. When that happens, the sequencer identifies which wells used a T or G molecule, indicating which base is next in the sequence. The assembly of these pieces of DNA is a major challenge and may require multiple runs through a sequencer before the complete sequence of the genome can be assembled.

\section{CGH arrays}

CGH arrays are used to study genomic copy number variations at high resolution [10-12]. Pieces of genomic DNA (bacterial artificial chromosome, PCR products representative of genomic sequences or cloned cDNA) with known chromosomal location and serving as target DNA are spotted on a glass slide. Test (cancer) and reference (normal) DNA are labelled with different fluorophores and simultaneously hybridised to clone the target chromosomal fragments. The ratio of fluorescence intensity of cancer to normal DNA is calculated to measure the copy number changes for a particular genomic location.

\section{SNP arrays}

SNP arrays allow accurate measurement of cancer-specific loss of heterozygosity in a high-throughput manner. Detecting loss of heterozygosity across the genome allows identification of patterns of allelic imbalance with potential prognostic and diagnostic utilities. It can also detect small regions of copy number alterations by producing genomic maps of high

\section{TABLE 1 Selected high-throughput technologies}

\begin{tabular}{|c|c|c|c|}
\hline \multicolumn{4}{|l|}{ Genomics } \\
\hline CGH arrays & $\begin{array}{l}\text { Sequences of genomic DNA (bacterial artificial } \\
\text { chromosomes, PCR products or cloned cDNA) }\end{array}$ & Up to 2 million probes & Copy number alterations \\
\hline SNP arrays & $\begin{array}{c}\text { Oligonucleotides (sequences of } 25 \text { bases } \\
\text { characteristic of a gene) }\end{array}$ & Up to 2 million probes & $\begin{array}{l}\text { Polymorphisms, loss of heterozygosity, } \\
\text { copy number alterations }\end{array}$ \\
\hline DNA methylation arrays & $\begin{array}{l}\text { Oligonucleotides covering whole genome or } \mathrm{CpG} \\
\text { islands }+ \text { /- promoters }\end{array}$ & Up to 385000 probes & DNA hyper- or hypo-methylation \\
\hline \multicolumn{4}{|l|}{ Transcriptomics } \\
\hline Gene expression arrays & Oligonucleotides or cDNA & Up to 385000 probes & Modification of gene expression levels \\
\hline miRNA expression arrays & Oligonucleotides (sequences of 8 to 9 bases) & Up to 1300 probes & Modification of miRNA levels \\
\hline Protein arrays & Lysates, proteins, peptides & Hundreds of probes & \\
\hline Tissue microarrays & Tissue biopsies & Hundreds of tissue specimens & \\
\hline
\end{tabular}

CGH: comparative genomic hybridisation; SNP: single-nucleotide polymorphism; miRNA: microRNA; MALDI-TOF MS: matrix-assisted laser desorption ionisation time-offlight mass spectrometry. 
resolution $[13,14]$. SNP arrays are commercially available in $10,000,100,000,500,000$ and up to 2 million SNP loci formats. They are synthesised by photolithography and contain up to 40 separate oligonucleotide probes for each SNP locus, representing both mismatch and perfect match probes. After DNA labelling and hybridisation, fluorescence intensities are measured for each allele of each SNP.

\section{Epigenomics}

Epigenomics is the large-scale study of epigenetic modifications, i.e. heritable changes in gene expression without DNA sequence alterations, mainly DNA methylation and histone post-translational modifications.

Different techniques are available for the detection of DNA methylation, based on the ability to distinguish cytosine from 5-methylcytosine in the DNA sequence, as follows: DNA digestion by a methylation-sensitive or -insensitive restriction endonuclease, DNA chemical modification by sodium bisulfite or metabisulfite, and 5-methylcytosine immunoprecipitation to separate the methylated and unmethylated fractions of the genome. All these techniques are now coupled to highthroughput technologies. Early epigenomic approaches used custom-made, slide-based arrays of CpG-rich regions corresponding to methylated or unmethylated DNA [15]. Later, because of their better precision and quantitative potential, the commercially available high-density oligonucleotide arrays were used [16].

So far, there is no high-throughput method to study histone modifications. However, chromatin immunoprecipitation-onchip technology is a microarray platform upon which immunoprecipitated DNA is hybridised against known probes; it allows the assessment of chromatin states [17].

\section{Transcriptomics}

Transcriptomics or global analysis of gene expression is the study of the transcriptome, the complete set of mRNA transcripts produced by the genome. The most common related high-throughput technologies are gene expression arrays (oligonucleotide and cDNA arrays) and microRNA (miRNA) expression arrays.

\section{Gene expression arrays}

Over the past 15 yrs, methods have been developed for the purpose of measuring semiquantitatively the relative abundance of transcribed genes in a given tumour sample [18]. Gene expression arrays mostly make use of matrix-bound probes to which processed mRNA templates of the analysed specimens will hybridise. Two major types of arrays have been developed for that purpose: oligonucleotide and cDNA arrays. While the former makes use of short oligonucleotides synthesised on the array matrix, the latter type of array employs probes of copy-DNA. Following hybridisation of a pre-processed and fluorescently labelled mRNA sample extracted from the tumour specimen, the arrays are scanned and transcript abundance is measured as a direct correlate of signal intensity. Following data normalisation, data can be analysed using a virtually unlimited array of computational and statistical methods. The two general approaches most commonly used for the study of cancer specimens involve methods for unsupervised clustering and supervised learning methods. While unsupervised methods allow self-organisation of data matrices according to similarity of features, supervised learning methods can yield gene sets or signatures of genes that can distinguish between a priori defined subsets of tumours. For example, one may define two groups of tumours according to clinical outcome ("poor survival" and "good survival" groups). Supervised learning methods, such as those involving K-nearest neighbour-based prediction methods can now help to identify those sets of genes whose transcriptional levels can best distinguish between the two groups [19]. In order to minimise the risk of overfitting the predictive signature, such approaches typically involve validation of the predictor in a separate dataset or by splitting the original dataset into a learning and test set. In the latter case, the predictor is built using the learning set and then validated in the test set. Also, the stability of the predictor is typically tested by random permutation of the data. By contrast, hierarchical clustering methods can help identify subgroups of tumours not known a priori that are characterised by a typical transcriptional signature.

\section{miRNA expression arrays}

miRNAs are single-stranded, small (18 to 24 nucleotides in length), noncoding RNAs that negatively regulate gene expression by binding to and modulating the translation of specific mRNAs. Each miRNA appears to regulate the translation of multiple genes, and many genes appear to be regulated by multiple miRNAs. miRNA microarrays enable the comparison of miRNA expression profiles of different tissues [20]. Total RNA from tumour and normal tissues are isolated and then gel fractionated using an electrophoresis system designed to speed up small RNA fractionation and isolation. miRNA fractions for each sample are labelled with different fluorophores. Labelled miRNAs are hybridised with slides arrayed with up to 1,300 distinct probes of eight to nine nucleotides. The ratio of fluorescence intensity of cancer to normal miRNA is calculated to measure the changes in expression levels for a particular miRNA sequence.

\section{Proteomics}

Proteomics is the large-scale study of proteins, particularly their structure and functions. Several high-throughput technologies have been developed.

\section{Two-dimensional gel electrophoresis}

This technique relies on polyacrylamide gels that separate proteins based first on their charge and then on their molecular weight. Gels are scanned with laser densitometers and analysed with software allowing the semiquantitative visualisation of $>500-1,000$ proteins per gel [21]. Individual protein spots of interest can be digested into peptides for sequence analysis by mass spectrometry (MS). A recent modification of this technique is the differential in gel-electrophoresis (DIGE), used to compare two protein mixtures from two different cell types directly on the same gel. The two pools are labelled with different fluorescent dyes, mixed together and run on the same gel [22]. Identical proteins from the two pools co-migrate and are independently detected by quantitative fluorometry. Differentially expressed proteins of interest are identified by alterations in the ratios of the two fluorescent signals. When samples are run on different gels, a third fluorescent dye is used as an internal standard allowing the 
normalisation of all spots across all gels. The standard is composed of a pooled sample containing equal amounts of both test and control samples.

\section{Matrix-assisted laser desorption ionisation time-of-flight MS}

Matrix-assisted laser desorption ionisation time-of-flight MS (MALDI-TOF MS) is a high-throughput technique that analyses with high sensitivity and specificity proteins expressed in complex biological mixtures, such as serum, urine and tissues $[23,24]$. It requires sample co-crystallisation with a matrix that absorbs laser energy and subsequently ejects and ionises molecules into the gas phase. Ions are then accelerated from the ion source by a fixed potential difference and travel a fixed-length, field-free distance before reaching the detector at a speed inversely proportional to their $\mathrm{m} / \mathrm{z}$ ratios (lighter ions are faster to reach the detector than heavier ions with the same charge). The time taken by each ion to hit the detector creates a signal and indicates an $m / z$ ratio of a given ion with a particular intensity. This methodology has been extensively applied to proteomic profiling of biological specimens as described below.

\section{Liquid chromatography tandem MS}

This technique combines high-performance liquid chromatography (LC) with electrospray ionisation MS, ionising and vaporising proteins from liquid solutions [25]. The multidimensional fractionation of biological samples coupled with this technique allows deeper interrogation of the proteome. The shotgun proteomic analysis platform uses digestion of the sample with site-specific proteases, multidimensional separation of peptides by strong cation exchange chromatography, such as in the multidimensional protein identification (MudPIT) technology [26-28] or isoelectric focusing [29, 30], followed by reverse phase (RP) LC separation coupled directly to a tandem MS instrument (MS/MS) (fig. 1). The most abundant peptides are sequentially selected for MS/MS analyses. Resulting fragment ions are then analysed in a second MS scan according to their $m / z$ ratios. Based on the fragments produced in the collision cell and their precise molecular weight, the peptides sequence can be derived [31]. Through comparisons with predicted sequences of same nominal mass in databases, peptides are identified and the proteins from which they came are deduced.

\section{Protein arrays}

Protein arrays offer an efficient way of simultaneously analysing multiple samples or proteins in a high-throughput manner. The two main forms are forward- and reverse-phase arrays. In forward-phase arrays, hundreds of specific antibodies, or bait proteins, are arrayed on a glass slide and one protein extract sample, representing one specific condition, is placed on the array. Expression levels or post-translational modifications of hundreds of proteins are analysed in a single experiment [32]. In reverse phase arrays, hundreds of tissue protein extracts or recombinant proteins are placed on glass slides and probed with a single antibody [33] or a drug candidate for drug development [34]. Expression levels of a given protein are evaluated in multiple samples.

\section{Tissue microarrays}

In tissue microarrays (TMAs), up to 3,000 cylindrical tissue biopsies $(0.6 \mathrm{~mm}$ in diameter) from individual tumours are distributed in a single paraffin block. Sections of the block provide targets for parallel in situ detection of DNA, RNA and proteins in each specimen on the array, and consecutive sections allow the analysis of hundreds of molecular markers in the same set of specimens $[35,36]$.

\section{Considerations for tissue collection}

The majority of the discovery efforts are based on the collection, storage and processing of tissue specimens obtained at the time of surgery, bronchoscopy or other diagnostic procedures. After informed consent, all biological specimens need to be collected under a standard operating procedure and quality control strategies must be in place to guarantee adequacy of the samples. This requires a concerted effort between clinicians, pathologists and research coordinators. Profiling using high-throughput technologies in biological fluids or tissue samples is best served by the use of fresh frozen materials. Tumour-derived markers are likely to be present at lower levels in blood and other biological specimens. Thus, the dynamic range of analytes concentration in biological specimens adds a critical dimension of technical considerations to the successful molecular analysis. Difficulties related to the lack of standardisation of the methodology, result in large variations between the results of different studies and making the translation of most discovery efforts to clinical practice difficult. To address these issues, huge efforts have been undertaken $[37,38]$, including the one at the Office of Biorepositories and Biospecimen Research (National Cancer Institute, Bethesda, MD, USA).

The use of formalin-fixed, paraffin-embedded tissue has many advantages. It allows the use of large collections of tissue available, which are fully annotated and easier to handle. Methods of extraction allow the recovery of quality DNA, RNA and proteins for high-throughput discovery and validation strategies. However, issues around the methods of preservation and the small amount of tissue available still render these efforts challenging [39]. Promising single-molecule sequencing and high-throughput oncogene mutation profiling represent strategies that may be applicable to small clinical samples in the future to address personalised medicine. However, before the next generation of sequencing enters clinical use, issues of cost, data analysis and interpretation will have to be resolved.

\section{BIOLOGICAL INFERENCES FROM HIGH-THROUGHPUT MOLECULAR ANALYSES OF LUNG CANCER \\ Discovery of critical mutations by systematic re-sequencing of genes in tumours}

An area that has recently provided a rich source of clinically relevant information is the systematic re-sequencing of genes in tumour specimens. These studies were inspired by the observation that genetically activated kinases represent excellent therapeutic targets. Kinases were among the most heavily sequenced genes in systematic cancer gene re-sequencing efforts. Early discoveries from these projects include the discovery of $B R A F$ mutations in thyroid, colorectal and lung cancers, as well as in a majority of malignant melanomas [40]. The fraction of $B R A F$-mutant lung cancers appears to be $<5 \%$ and to be exclusively restricted to lung adenocarcinomas [41]. This observation has led numerous pharmaceutical companies 

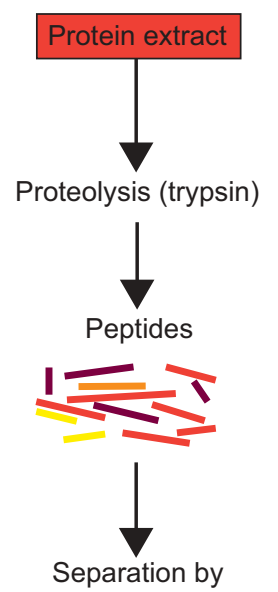

multidimensional liquid chromatography

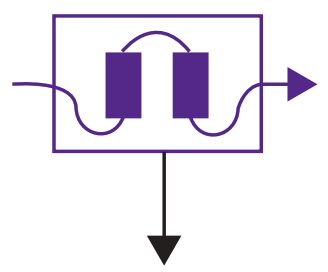

MS1: $m / z$ separation (peptide molecular weight determination)

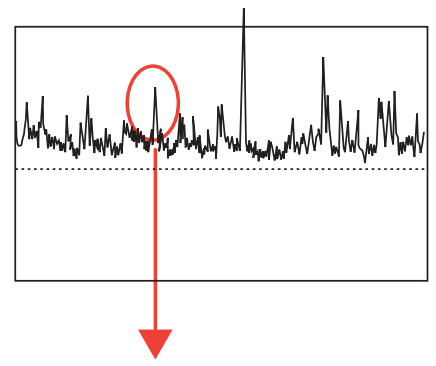

Transmission of one peptide
Protein identification

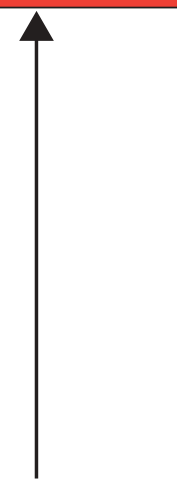

Database search

Correlation molecular weight and fragmentation pattern

$[1,2, \ldots n]$

Computer cluster

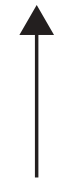

MS2: $m / z$ separation (fragmentation spectrum)

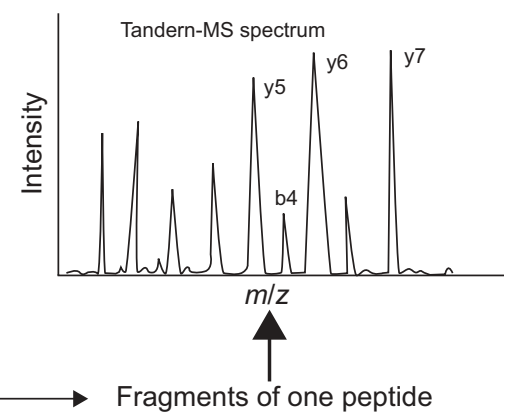

FIGURE 1. Schematic representation of "bottom up" or shotgun analysis. A protein mixture is first digested (by trypsin) and the resulting peptides are separated by multidimensional liquid chromatography (typically strong cation exchange followed by reverse-phase separation) coupled online to a mass spectrometer. As they elute, the $\mathrm{m} / \mathrm{z}$ ratios of the peptides are first determined, followed by one or several mass spectrometry (MS)/MS scans from the most abundant peptide signals (y5, y6 and $y 7$ are $m / z$ values for "y-ions" and b4 is the $m / z$ value for a "b-ion". The fragment peaks that appear to extend from the amino terminus are termed "b" ions, and those that appear to extend from the C-terminus are termed "y ions"). This cycle is repeated until all of the peptides have eluted from the chromatography column. For each precursor peptide selected for MS/MS, peptides of similar nominal mass are extracted from sequence databases and predicted fragmentation patterns are derived in silico. These patterns are then compared with the experimental fragmentation spectrum to generate correlation scores. Positive identification of a protein is based on the observation of two or more peptides issued from its sequence.

to launch drug discovery programmes dedicated to specific targeting of $B R A F$-dependent tumours. Trials investigating the efficacy of these agents are ongoing in several tumour types [42]. Whether BRAF-mutant lung cancer can be successfully treated with inhibitors targeting downstream pathway members of $B R A F$ remains to be established. In another study, mutations in the gene encoding the catalytic subunit of the class-1a phosphoinositide- $(3,4,5)$-kinase $(P I K 3 C A)$, were found in a large fraction of epithelial cancers [43]. While frequency of these mutations was found to be $<5 \%$ in lung cancer, PIK3CA is the most frequently mutated oncogene in breast cancer and is also frequently mutated in colorectal cancer. In several functional analyses, these mutations were found to be oncogenic by activating the Akt survival pathway [44]. Most recently, preclinical studies involving new generation phosphoinositide $(P I) 3$-kinase inhibitors suggest that tumours carrying these mutations might be exclusively sensitive to such treatment [45]. Since some of these agents are currently being developed in early clinical trials, there is considerable hope that they might be clinically efficient in multiple solid tumours. This hope is supported by the observation that tumours driven by oncogenically activated receptor tyrosine kinases frequently exhibit activation of the PI3-kinase / Akt pathway.

The most groundbreaking discovery made in these projects was the finding that the receptor tyrosine kinase epidermal 
growth factor receptor (EGFR) is mutated in $\sim 10 \%$ of Caucasian and up to $40 \%$ of East-Asian patients with NSCLC [46-49]. These mutations were enriched in patients who were of East-Asian ethnicity, who had never smoked and whose tumours were of lung adenocarcinoma histology. These features were closely related to those of patients who had experienced responses when treated with the EGFR tyrosine kinase inhibitors erlotinib or gefitinib. In fact, exon resequencing revealed mutations in the EGFR kinase domain in responders to gefitinib or erlotinib but not in nonresponders. Thus, mutant EGFR appeared to be an additional example of successful therapeutic targeting of oncogenically activated tyrosine kinases. Unfortunately, all patients initially responding to EGFR inhibitors will eventually relapse. Systematic genetic analyses of tumour biopsies obtained at the time of relapse revealed a second site mutation of EGFR as the causative mechanism. This mutation, T790M, is analogous to the T315I mutation of $A B L$, causing acquired resistance in chronic myeloid leukaemia patients who initially responded to imatinib [50-52]. Functional cell and structural biology studies have now proven, on a formal level, the causative nature of the T790M mutation in acquisition of resistance. An additional mechanism of acquired resistance is the de novo amplification of the MET receptor tyrosine kinase gene $[53,54]$. Importantly, this mechanism was identified using in-depth cell biology and cancer genome analyses in cell line experiments and subsequently validated in patient specimens. This discovery, therefore, further supports the use of cell line experiment as preclinical proxies with substantive clinical relevance.

Numerous trials have been performed since the discovery of EGFR mutations in lung cancer with the goal of defining the role of EGFR mutations' detection as a tool to select patients for treatment with EGFR inhibitors. Although a detailed discussion of the results from these trials is beyond the scope of this review, we would like to highlight some central results. Importantly, trials selecting patients based on the presence of EGFR mutations or on clinical characteristics of EGFR mutations (Asians, never-smokers, adenocarcinomas) consistently yielded response rates exceeding $70 \%$ and led to median overall survival exceeding 20 months [55-59]. Although these results led to widespread excitement in the community, as they suggested an effective treatment for a significant subgroup of lung cancer patients, it was suggested that EGFR mutations were prognostic rather than predictive. These results were initially supported by a study by EBERHARD et al. [60] suggesting that EGFR-mutant patients had a better overall survival independent of treatment. The study by EBERHARD et al. [60] was recently confirmed by findings of the Iressa Nonsmall cell lung cancer Trial Evaluating REsponse and Survival against Taxotere (INTEREST) trial [61], which failed to show a benefit in overall survival for EGFR-mutant patients with gefitinib. In fact, progression-free survival in this trial was significantly better for EGFR-mutant patients receiving gefitinib. Most recently, the results from the IRESSA Pan Asia Study (IPASS) trial [62] comparing gefitinib and carboplatinum plus docetaxel in East-Asian never- or ex light-smokers with adenocarcinomas were reported. This trial not only confirmed a clear survival benefit for EGFR-mutant patients treated with gefitinib but also showed that EGFR mutation-negative patients receiving gefitinib had the worst prognosis.
Altogether, these findings show that EGFR mutations are in fact predictive for treatment outcome in patients receiving EGFR inhibitors and that patients without EGFR mutations should not be treated with these agents; thus, EGFR mutation testing should be mandatory before treating lung cancer patients with EGFR inhibitors.

In independent studies, EGFR copy number gain and amplification were found to be better markers of treatment outcome in patients receiving gefitinib or erlotinib than the presence of EGFR mutations [55, 63-65]. However, concerns were raised with respect to the methods used for mutation detection and for criteria of copy number assessment. Furthermore, mutation detection using conventional sequencing methods is hampered by low sensitivity, in particular in samples with high admixture of nontumoural cells (see following section). In contrast, detection of chromosomal copy number gains is far less sensitive to sample impurity. Given the fact that EGFR mutations are highly correlated with EGFR copy number gains and amplifications ([66] and R.K. Thomas, Max Planck Institute for Neurological Research, Köln, Germany; personal communication), it is tempting to speculate that findings suggesting a predictive role for EGFR copy number gains/amplifications might be reflective of the low sensitivity in EGFR-mutation detection.

One important issue to consider when interpreting results from studies reporting the frequency and clinical relevance of somatic oncogene mutations is the fact that the most widely used method for mutation detection in cancer specimens, dideoxy nucleotide sequencing [67], is hampered by low sensitivity. In particular, this applies to samples with an admixture of nontumoural cells, a typical feature of most biopsy specimens analysed in the clinic. For example, in a patient series of 22 specimens enriched for the presence of EGFR mutations that had been previously heavily sequenced using the Sanger method [47], definite determination of EGFR mutation prevalence showed that conventional sequencing had missed three mutations [68]. By contrast, recently developed genetic analyses methods that were originally designed to enable rapid genome sequencing afford accurate and independent sampling of all allele species present within a given tumour specimen. Using the array-based picotitre pyrosequencing-by-synthesis technology developed by 454 LifeSciences (Roche Diagnostics, Base, Switzerland), oncogene mutations were discovered in samples where conventional sequencing had failed to do so. This approach accurately detected mutations in formalin-fixed, paraffin-embedded tissue specimens [68]. Furthermore, it yielded accurate mutation diagnosis at extreme sensitivity (e.g. down to allelic representations of $1 \%$ ) and allowed the identification of the gatekeeper mutation T790M, associated with resistance to EGFR inhibitors, in malignant pleural effusion specimen (fig. 2). Thus, the dramatic limitations of conventional sequencing can easily be overcome employing novel genome analytics when used in the context of clinical genetic diagnostics.

In another project termed OncoMap, genotyping assays were designed for $>200$ known oncogene mutations in 17 oncogenes covering multiple classes (e.g. receptor tyrosine kinases, intracellular tyrosine kinases, serine-threonine kinases and small GTPases). A mass spectrometric genotyping method (Sequenom) was applied to genotype this panel of oncogene 


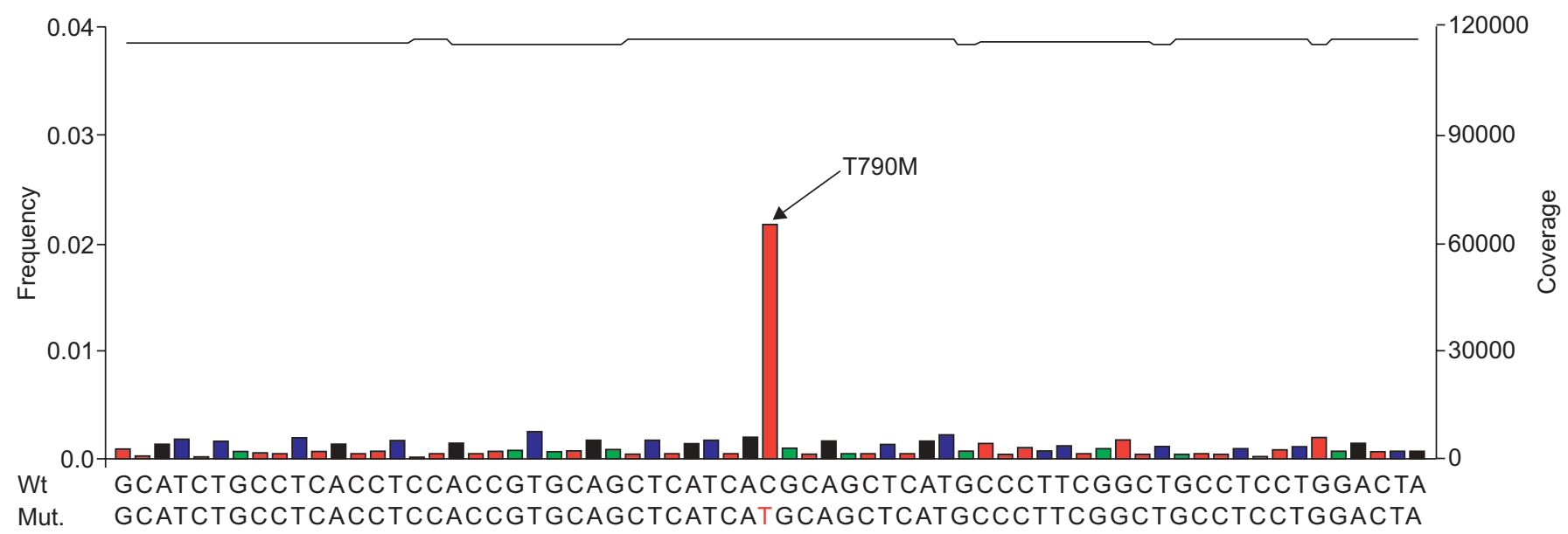

FIGURE 2. Sequencing of DNA from cells recovered in a pleural effusion specimen obtained th the time of acquired erlotinib resistance. After PCR amplification of exon 20, 454 sequencing revealed the presence of the T790M resistance mutation of epidermal growth factor receptor (EGFR) [49] at 2\%. Robust calling of T790M carrying EGFR alleles was ensured by $>60,000 \times$ over-sampling. Wt: weight; Mut.: mutation. —_: coverage; green: A; blue: C; black: G; red: T. Reprinted from [68], with permission from the publisher.

mutations across 1,000 human cancer specimens, covering multiple tumour types. This approach was highly accurate, sensitive and specific. Most importantly, due to the scalability and rapidity of this method, we were able to profile all 1,000 tumours within a few weeks of the time of the experiment and at a reasonable cost [69].

The efforts to fully characterise the genomes of major human cancer types [70-74] revealed that beyond known cancerrelated genes, many additional genes are mutated in individual cancers. However, most of these mutations occurred only in a single tumour, suggesting that each tumour is composed of an individual set of mutations contributing to tumorigenesis. The average number of mutations per tumour of a given entity ranged from 48 in pancreatic cancer to 101 in breast cancer [71]. Ultimately, functional cell biology experiments will be required to establish the individual contributions of these mutations to oncogenic transformation. Such efforts will need to afford assaying cell biology at high-throughput in order to cope with the multitude of genetic lesions discovered by highthroughput cancer genome profiling.

Finally, technologies are being developed that will help to potentiate the throughput and sensitivity in genome sequencing. When considering that in contrast to discovery-oriented genome profiling projects that employ specimens enriched for high tumour content, the prototypical diagnostic specimen in the clinic is a small piece of formalin-fixed transbronchial biopsy with large amounts of necrosis and numbers of inflammatory cells. Technologies such as single-molecule sequencing or high-throughput oncogene mutation profiling represent good examples of how these problems can be tackled in order to ensure accurate diagnosis and optimal patient stratification for targeted therapy.

\section{Stable genomic alterations in lung tumours measured by array CGH tell us about tumour behaviour}

Over the last 10 yrs, we have learned that somatic molecular alterations in cancers yield signatures that can be used for sub-classification [75-77], and that they provide information relevant to predicting patient survival $[75,78]$, risk of recurrence [79] and response to therapy [76, 80]. Nevertheless, NSCLC is still largely managed as a single major entity using similar preventive, diagnostic and therapeutic approaches. Chromosome abnormalities often correlate with molecular abnormalities and provide a starting point for gene discovery and characterisation in the context of a specific disorder [81]. In cancer biology, chromosomal abnormalities carry diagnostic, prognostic and predictive value of response to treatment. The Cancer Gene Consensus of the Cancer Genome Project at the Sanger Institute [82] contains 363 cancer genes, among which 292 are oncogenes otherwise commonly activated by translocation. Recent studies report 138 hot spots of genomic amplification (across 104 human cancer cell lines) [83]. The authors identified $\sim 50 \%$ of putative oncogenes in the previous study showing genomic amplification. In lung cancer cell lines, an average of 32 regions of amplification was detected per genome. Taken together, these data suggest that genomic amplification may be a common mechanism of oncogene activation.

The use of array CGH based on high density of bacterial artificial chromosome clones, cDNA microarrays, oligonucleotide arrays or SNP arrays combined with mRNA expression arrays has greatly improved the resolution of traditional CGH and has facilitated identification of new candidate genes across the genome [84-87]. Among the prevalent chromosomal changes in lung cancer, chromosome $3 q$ amplification is one of the most frequent and is an early event in lung as well as in aero-digestive tract tumours [88, 89]. The amplification of the distal portion of chromosome $3 q$ in lung cancer is a major signature of neoplastic transformation [90]. It is found in early stages of lung cancer development, including severe bronchial dysplasia, and is maintained throughout the progression of cancer as well as in metastatic stages [91]. A causal relationship between smoking history and $3 q$ amplification has been suggested but has not yet been proven. The size of the amplicon varies greatly between tumours and spans from chromosome $3 q 22$ to 3qter, with a most frequent region of 
amplification in squamous cell carcinoma between $3 q 26$ and $3 q 29$ ( $35 \mathrm{Mb}$ ). High-throughput technologies will eventually allow the integration of complex molecular analyses and shed light on the role of this amplicon in lung cancer.

\section{Airway epithelium in the field of carcinogenesis: the oncogenic battleground}

Carcinogen exposure induces diffuse epithelial injury, with genetic changes and premalignant/malignant lesions in one region of the field representing an increased risk of cancer development in the entire field. The impact of smoking on airway transcriptome has been the subject of recent investigations.

One of these investigations, using Affymetrix HG-U133A and HG-U133 Plus 2.0 arrays (Affymetrix, Santa Clara, CA, USA) to study small airway bronchial epithelium, found 300 genes significantly up- or down-regulated in phenotypically normal smokers $(n=16)$ compared to matched nonsmokers $(n=17)$, including genes coding for response to oxidants and xenobiotics, immunity and apoptosis [92]. Moreover, variability in small airway epithelium gene expression among phenotypically normal smokers was shown, suggesting a genetic factor in response to smoking $[93,94]$.

Patterns of gene expression that occur in bronchial airway epithelial cells obtained via bronchoscopy from healthy current, former and never-smokers have also been explored by highdensity oligonucleotide microarray analysis [95]. Airway epithelial cells were obtained by brushing of the main stem bronchus. RNA was isolated, processed and hybridised onto the Affymetrix HG-U133A array. In that study, Spira et al. [95] identified gene expression changes that occur in response to smoke exposure and demonstrated that the expression of a number of genes correlated with cumulative tobacco exposure. Using Affymetrix HG-U133A microarrays, the same group performed gene expression profiling of histologically normal large airway (main stem bronchus) epithelial cell brushings obtained from current and former smokers undergoing flexible bronchoscopy as a diagnostic study for the suspicion of lung cancer at four medical centres [96]. Each subject was followed until a final diagnosis of lung cancer or an alternate diagnosis was made. In a training set of 77 samples, they identified an 80gene biomarker that distinguishes smokers with and without lung cancer. The biomarker was tested on an independent test set $(n=52)$, with an accuracy of $83 \%$ ( $80 \%$ sensitive, $84 \%$ specific), and subsequently validated on prospective series independently obtained from five medical centres $(n=35)$. These results suggest that tobacco smoke induces a cancer-specific field of injury throughout the airway epithelium, with potential value as a marker of diagnosis and/or risk. More recently, the same group used a clinical and combined genomic model that proved the biomarker independence from other clinical factors and showed its higher prediction accuracy (fig. 3) [97]. In patients with suspicion of lung cancer, this marker may improve the diagnostic sensitivity of histological assessment and reduce the use of additional diagnostic tests that are invasive and expensive. Moreover, it could be tested as a candidate biomarker of risk of lung cancer development and as intermediate end-point biomarker of response to chemopreventive strategies.

\section{Potential of gene expression profiles to analyse oncogenic pathways}

Carcinogenesis is a complex process characterised by the accumulation of multiple independent genetic alterations, often involving overexpression of oncogenes and loss of tumour suppressor genes. These genetic alterations disrupt the normal regulation of cell signalling pathways, essential for the control of cell growth, differentiation and apoptosis. Several studies have demonstrated the potential of gene expression profiles to analyse oncogenic pathways and to describe the complexity of cancer phenotype [98-102].

In a recent study, gene expression profiles characterising activated pathways were found after infection of quiescent primary mammary epithelial cells with adenovirus to express relevant genes and artificially activate pathways of interest [103]. The ability of each signature to accurately assess the corresponding pathway status was verified by internal validation measures, by the use of three mouse tumour models (mouse mammary tumour virus-Myc, Ras, E2F3) and by use of adult mouse tumours in which Ras activity was activated by homologous recombination. Pathway activities were then evaluated in NSCLC samples. Ras pathway deregulation was found in most adenocarcinomas as opposed to squamous cell carcinoma, suggesting its role in adenocarcinoma development. Tumours with high Ras activity were also predicted to have low levels of Myc, E2F3, $\beta$-catenin and Src activity, and vice versa. Patients with deregulation of Ras associated with $\beta$ catenin, Myc and Src constituted a poor survival population. Finally, investigators successfully used the pathway deregulation signatures to predict sensitivity to therapeutic agents targeting the corresponding pathways in cancer cell lines. This study is a good illustration of how integrated pathway analysis develops our understanding of carcinogenesis. Moreover, this

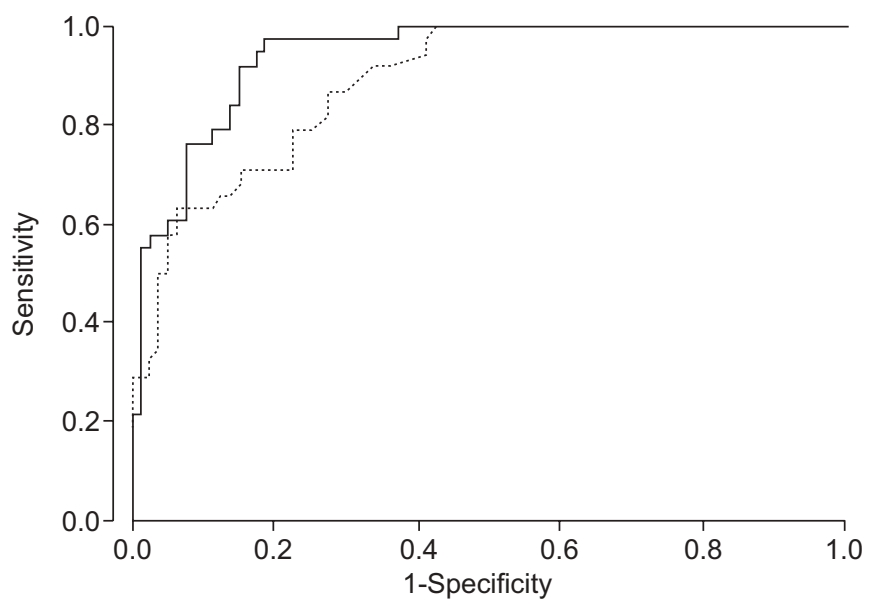

FIGURE 3. Added value of genomic to a clinical model predictive of lung cancer. Receiver operating characteristic curves of the combined training and test sets $(n=118)$, consisting of smokers undergoing bronchoscopy for suspicion of lung cancer. The clinical model $(\cdots \cdots)$ includes three variables: age, mass size and lymphadenopathy; the clinicogenomic model (_- includes the previous variables and the biomarker score. The area under the curve for the clinical and clinicogenomic models is 0.89 and 0.94 , respectively, which represents a significant difference between the two curves $(p<0.05)$. Reproduced from [97], with permission from the publisher. 
approach may be helpful for a better categorisation of patients with lung cancer, in terms of histology and also outcome, in an attempt to address the need for personalised therapy. Finally, this strategy represents a promising tool to guide the use of combined targeted therapies.

\section{Role of epigenetic events in tumour progression}

Recently, it is becoming clear that epigenetic events, such as DNA methylation and histone modifications, are also central to tumour progression.

Genomic DNA hypomethylation, leading to genomic instability, as well as aberrant promoter hypermethylation, leading to inactivation of tumour suppressor genes [104], have been shown to be common events in human cancers. In patients with lung cancer, promoter hypermethylation has been detected in blood [105], bronchial lavages [106], induced sputum [107] and pleural fluid [108]. TP16 promoter methylation was found in sputum of smokers up to 3 yrs before their clinical diagnosis of squamous cell carcinoma [109], and has thus been proposed as a biomarker for early detection of lung cancer and monitoring of prevention trials [110, 111]. Furthermore, methylation of the promoter region of four genes (TP16, CDH13, RASSFIA and APC) in patients with stage I NSCLC was associated with early recurrence (fig. 4) [112]. With the development of high-throughput technologies, novel target genes for aberrant methylation have been identified $[113,114]$. Protein expression of one of them, OLIG1, correlated significantly with survival in lung cancer patients [115].

Chromatin is an important player in gene expression regulation, and alterations in its structure have been linked to cancer development, through DNA methylation and also histone hyper- or de-acetylation (depending on the target gene). The acetylated state of histones is associated with transcriptional activity, and it has been shown that active histone acetylation plays a role in re-expression of silenced tumour suppressor

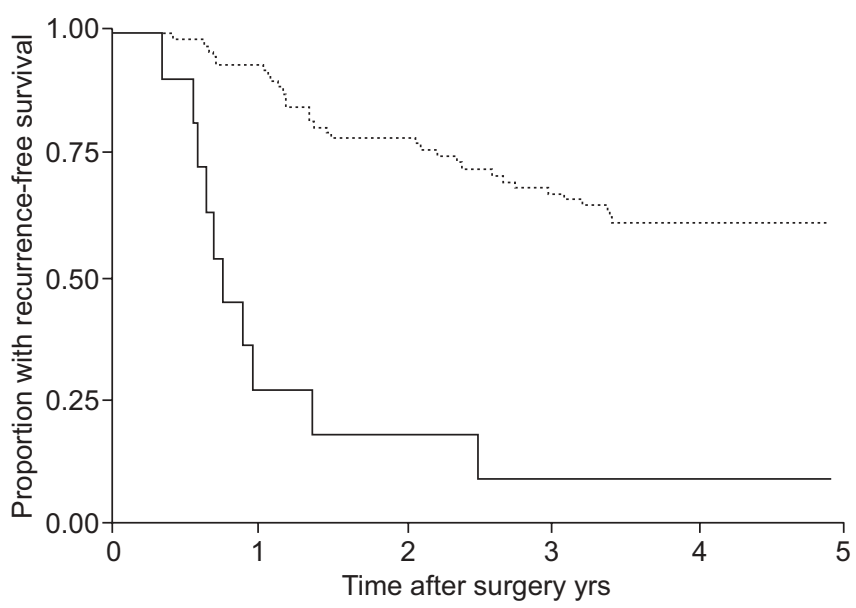

FIGURE 4. Methylation of the promoter region of TP16 and $\mathrm{CDH} 13$ in patients with stage I nonsmall cell lung cancer is associated with early recurrence. When both TP16 and CDH13 were methylated in the tumour and the mediastinal nodes, there was a significantly lower rate of recurrence-free survival $(9.1 \%$ (95\% Cl $0.5-$ 33.3)) than if TP16 and $\mathrm{CDH} 13$ were unmethylated $(61.2 \%(95 \% \mathrm{Cl}, 49.7-70.9)$; $p<0.001)$. — : methylated $(n=11) ; \cdots \cdots \cdot$ : unmethylated $(n=80)$. Reproduced from [112], with permission from the publisher. genes [116]. Recent studies indicate an antitumour activity of histone deacetylase inhibitors against NSCLC [117-119].

\section{Alterations of miRNA expression may deregulate cancer- related genes}

Through gene expression regulation, miRNAs seem to be involved in diverse cellular functions, such as proliferation, differentiation, death and stress resistance [120]. Expression levels of miRNAs have been reported to be dysregulated in human cancer, suggesting a role in oncogenesis.

In a study analysing 104 pairs of NSCLC and corresponding normal lung tissues, an expression profile of 43 miRNAs discriminated lung cancers from noncancerous lung tissues [121]. Six miRNAs (hsa-mir-205, hsa-mir-99b, hsa-mir-203, hsamir-202, hsa-mir-102 and hsa-mir-204-prec) were differentially expressed in adenocarcinomas and squamous cell carcinomas, with higher expression levels of hsa-mir-99b and hsa-mir-102 in adenocarcinomas. Furthermore, high hsa-mir-155 and low hsalet-7a-2 expression correlated with poor survival in lung adenocarcinomas $(p=0.033)$. This observation was confirmed by RT-PCR analysis and cross-validated with an independent set of adenocarcinomas. In another study of 143 surgically resected NSCLC, low let-7 expression was also significantly associated to shorter survival $(\mathrm{p}=0.0003)$; and overexpression of let-7 in A549 lung adenocarcinoma cell line inhibited lung cancer cell growth in vitro [122].

Differentially expressed miRNA genes in NSCLC are frequently located in fragile sites and/or chromosomal regions with frequent copy number alterations, suggesting that differences in miRNA expression may be induced by genomic alterations. However, since $>50 \%$ of miRNAs are located at cancer-related chromosomal regions, miRNAs are also suspected to play a role as oncogenes or tumour suppressor genes. miRNA expression profiles represent potential markers for lung cancer diagnosis, classification and prognosis. However, inconsistencies between studies are observed, probably due to technical and analytical differences, as well as lack of standardisation.

\section{Importance of proteomics to detect post-translational modifications}

Post-translational modifications of proteins, such as phosphorylation, glycosylation and proteolytic processing, are common events and have the potential to significantly modify protein functions as well as confer cellular or tissue specificity. Unlike genomic analysis, proteomic analysis has the ability to detect these modifications.

An illustration of the importance of post-translational modifications is provided by tyrosine kinase signalling, which is often deregulated in cancer. In a study using a phosphoproteomic approach based on phosphopeptide immunoprecipitation and analysis by liquid chromatography-tandem mass spectrometry (LC-MS/MS), the tyrosine kinase signalling was characterised across 41 NSCLC cell lines and 150 NSCLC tumours [123]. Kinases already known as oncogenes (e.g. EGFR and c-MET), as well as kinases never previously implicated in NSCLC (PDGFR and DDR1) were identified. In the actual era of tyrosine kinasebased targeted therapies, the insights provided by this study are particularly interesting. 
As discussed before, histone modifications represent another example of post-translational modifications contributing to carcinogenesis. Since post-translational modifications are reversible, drugs inhibiting these modifications are developed and hold great promise for lung cancer therapy. Proteomic strategies have an important role by allowing not only the identification of post-translational modifications, but also the quantification and monitoring of the changes induced by their inhibitors.

\section{Involvement of glycans in cancer biology}

The technique of glycomics addresses sugars, whether free or present in complex molecules such as proteins or lipids. Sugars drive a series of molecular processes that are related to cancer development. The following few examples illustrate this point.

Mucins are highly O-glycosylated proteins synthesised by epithelial cells, and their glycosylation patterns can be altered during inflammation or neoplastic transformation. Peritumoural epithelium and squamous metaplasia show an abnormal pattern of mucin expression. However, squamous cell carcinomas and adenocarcinomas display a similar pattern of mucin gene expression, supporting the concept of a common cellular origin [124]. Recent results have uncovered a new link between death-receptor $O$-glycosylation and apoptotic signalling. O-glycosylation of DR4 and DR5 promotes ligandstimulated clustering of DR4 and DR5, which mediates recruitment and activation of caspase-8 [125].

$\mathrm{N}$-glycans of receptors or adhesion molecules are considered to be involved in cellular functions by altering their functions such as cell signalling and cell adhesion, which are implicated in cancer invasion and metastasis [126]. For example, lack of core fucosylation of the EGFR leads to the suppression of epidermal growth factor (EGF) signalling and cell growth [127]. $N$-glycosylation profiling of blood proteins by MS has been shown to be valuable in proof of concept studies in, for example, pancreatic cancer [128]. Defining serum glycan profiles for normal, invasive and preinvasive lesions might have important diagnostic, prognostic and therapeutic implications. Lectins represent highly versatile carbohydrate-binding proteins that are employed for the profiling of glycoproteins [129]. This is an emerging field that currently suffers in its applications (for glycoprotein enrichment and glycan profiling) from great variability across platforms and laboratories.

Glycoproteins in human serum play critical roles in many biological processes [126, 130,131] and also have clinical value as biomarkers for disease progression and treatment [132]. For example, glycoproteins have been isolated from the sera using multilectin affinity chromatography, digested first by peptide- $N$-glycosidase $\mathrm{F}$ and then by trypsin. Peptides have been analysed by nano-LC-MS/MS and the majority of identified proteins were found to contain more than one potential glycosylation site. Comparison of the serum glycoproteome of healthy and adenocarcinoma individuals revealed 38 cancer-selective proteins [133]. Their value as candidate biomarkers needs to be tested in prospective studies. In another dataset from 180 patients with unresectable and metastatic NSCLC enrolled in six docetaxel phase II studies at $100 \mathrm{mg} \cdot \mathrm{m}^{-2}$, alpha1-acid glycoprotein was found to be an independent predictor of response with an odds ratio of 0.44 $(p=0.0039)$ [134]. Sialylated glycoprotein IL-6 has been shown to predict poor prognosis in patients with EGFR-mutated NSCLC treated with gefitinib [135]. Tumours expressing a high level of certain types of tumour-associated carbohydrate antigens (TACA) exhibit greater metastasis and progression than those expressing low level of TACA, as reflected in decreased patient survival rate [136].

Glycomics is a new field of interest in lung cancer research, holding great promise for the development of biomarkers and therapeutic targets. However, this area of research is challenged by an inherent level of complexity and requires improvements in molecular sequencing and bioinformatics.

\section{Lipidomics as a promising area of cancer research}

The progress made in genomics and proteomics has been led by novel analytical approaches, which have been slower to appear for the analysis of lipids and their biology. LC and MS are now making this field a promising area of biomedical research [137]. Lipids have a prominent biology in lungs as surfactants [138] and prostanoids [139], and in phospholipid signalling-related cancer biology (e.g. PI3-kinase [140]). Immunohistochemical studies have shown that human bronchial dysplasia and atypical adenomatous hyperplasia express high levels of fatty acid synthase (FAS) when compared with normal lung tissues [141]. This suggests that FAS might be a target for intervention in lung carcinogenesis. Thus, lipidomics represents a promising area of biomedical research, with a variety of applications in drug and biomarker development.

\section{SELECTED APPLICATIONS OF HIGH-THROUGHPUT TECHNOLOGIES TO ADDRESS CLINICAL QUESTIONS Lung cancer risk assessment}

While $80-90 \%$ of lung cancers are attributable to cigarette smoking, only a minority of smokers will develop lung cancer $[142,143]$. In addition, $10-20 \%$ of cases occur among neversmokers and a familial risk has been described [144]. This suggests gene-environment interactions in disease development, as well as different molecular mechanisms in smokers and never-smokers. Selective expression of EGFR mutations in never-smokers with NSCLC supports this hypothesis.

The familial occurrence of lung cancer has been investigated in a genome-wide linkage analysis of 52 extended pedigrees of lung cancer patients with several affected relatives, which localised a lung cancer susceptibility locus at 6q23-q25, containing many genes of interest (SASH1, LATS1, IGF2R, PARK2 and TCF21) [145], some of which seem to be frequently inactivated by methylation [146, 147]; however, no tumour suppressor genes inactivated by mutation have been identified in this locus.

Several case-control studies that focused on genes with susceptibility to modify the risk were conducted to address why only a minority of smokers develop lung cancer, and found polymorphisms in carcinogen-metabolising enzymes [148] and DNA repair enzymes [149, 150], as well as in genes with impact on smoking behaviour [151]. Recently, a genome-wide association study was conducted to identify common low-penetrance alleles influencing NSCLC risk [152]. Investigators analysed 315,450 tagging SNP in 1,154 ever-smoker lung cancer patients 
and 1,137 matched ever-smoker controls. The 10 SNP most significantly linked with lung cancer were tested in two additional large datasets. They found two SNP significantly associated with lung cancer risk, both of them located in the chromosomal region 15q25.1, and homing three genes: CHRNA3 and CHRNA5 (nicotinic acetylcholine receptor alpha subunits 3 and 5) and PMSA4 (proteasome alpha 4 subunit isoform 1). While there is no current evidence for a role of PMSA4 in lung cancer, the nicotinic acetylcholine receptor pathway has been implicated in lung cancer pathogenesis and progression [153155]. Two other large genetic epidemiological studies reported very similar results, illustrating the gene-environment interaction in lung cancer and further incriminating this genomic region in the pathogenesis of lung cancer [156, 157]. Taken together, these data suggest nicotinic acetylcholine receptors to be potential chemopreventive targets.

Further studies are needed to elucidate the mechanisms responsible for lung cancer development, and subsequently permit the identification of patients at risk of developing lung cancer. This selected population may benefit from chemoprevention and careful surveillance, which may ultimately improve outcome.

\section{Blood-based early detection and noninvasive diagnosis of lung cancer}

The discovery of biomarker signatures or panels for lung cancer diagnosis is crucial, as a single biomarker is unlikely to be specific and sensitive enough on its own to demonstrate clinical utility. These new emerging technologies, combined with the assumption that circulating proteins/peptides are deriving from the perfusion of tumours, have revived a longterm interest in analysing the blood proteome of cancer patients. Since blood access is easy, fast and amenable to repetitive measurements, this biospecimen appears very attractive for the application of biomarkers to early diagnosis of lung cancer, monitoring of disease status, development of targeted therapies, evaluation of response to therapy and survival. It may improve our diagnostic accuracy and decrease the number of thoracotomies currently required for pathological evidence of malignant cells.

Several serum biomarkers have already been investigated in lung cancer but have not been proven useful in clinical practice because of their limited sensitivity and/or specificity, especially in early-stage disease [158-160].

A team of investigators assayed six serum proteins, four discovered by proteomics (2DIGE and MALDI-MS) and two previously known to be cancer-associated, on a training set of sera from 100 patients (50 lung cancers, 50 controls) [161]. They found that four of these proteins (carcinoembryonic antigen, retinol binding protein, $\alpha 1$-antitrypsin and squamous cell carcinoma antigen) were able to distinguish lung cancer cases from controls with $89.3 \%$ sensitivity and $84.7 \%$ specificity. When applied to an independent validation set (50 lung cancers, 50 controls), the four-protein signature achieved $77.8 \%$ sensitivity and $75.4 \%$ specificity, while none of the four markers had sufficient diagnostic power when used alone. MALDI-MS was also used to analyse undepleted and unfractionated sera from a total of 288 NSCLC patients and controls divided into training (92 cases, 92 controls) and test (50 cases, 56 controls) sets [162]. A seven-signal proteomic signature was found, distinguishing lung cancer cases and controls with $78 \%$ accuracy, $67.4 \%$ sensitivity and $88.9 \%$ specificity in the training set; and $72.6 \%$ accuracy, $58 \%$ sensitivity and $85.7 \%$ specificity in the test set. Moreover, the serum signature was associated with lung cancer diagnosis independently of the smoking history and levels of C-reactive protein, a marker of inflammation. Although MS-based proteomic analysis of lung cancer allowed the discovery of novel diagnostic biomarkers, their application is still limited to laboratory use. Therefore, population studies are required for their translation into the clinic.

\section{Lung tumour class discovery and class prediction}

Microarray analysis of NSCLC samples combined with a class discovery approach showed that gene expression profiles were able to accurately classify tumours into their classical histological groups, and also to identify histological subgroups [163166]. This information is important as therapeutic options can be different among the histological groups and even subgroups. Using Affymetrix U133A gene chips (Affymetrix, Santa Clara, CA, USA) to analyse 129 squamous cell carcinomas, a study defined two squamous cell carcinoma subgroups, with different overall survival [167]. Three other studies found adenocarcinoma subgroups [76, 164, 168]. Each of these three studies defined a different number of adenocarcinoma subgroups, questioning the reproducibility and consistency of tumour classification by gene expression microarrays. Sample heterogeneity, sample size differences and analytical platform differences can explain some of these results [169].

Proteomics tumour profiling also allowed tumour class prediction and discovery. When profiling 79 NSCLC and 14 normal frozen lung tissue sections by use of MALDI-TOF MS, differentially expressed MS signals were selected and a class prediction model using established methods was defined [170]. Investigators found a 75\% accurate signature allowing lung tumours classification by histology [171]. They extended this approach to the analysis of preinvasive lesions to distinguish low-grade from high-grade preinvasive lesions [172]. These efforts have not yet lead to applications in clinical practice. Validation of these biomarker candidates will require prospective validation in larger studies, across institutions and laboratories, and will have to prove clinical utility in the current management of lung cancer.

\section{Prediction of prognosis}

Prediction of prognosis may improve the management of patients with lung cancer by identifying those who are more likely to benefit from treatment.

Gene expression profiles have shown the potential to predict lung cancer patient survival. Indeed, in a study analysing 86 adenocarcinomas, 50 genes were differentially expressed between low- and high-risk patient groups [75]. The results were validated in an independent dataset made of 62 adenocarcinomas. Several stage I lung cancer patients were clustered with stage III patients into the poor prognosis group, showing that the gene expression profile was independent of the pathological stage at time of diagnosis, therefore providing an added prognostic value. A 37-gene signature predicting 
prognosis was also identified in a cohort of 86 adenocarcinomas [173]. When applied to an independent cohort of 84 adenocarcinomas, the signature separated patients into three prognostic groups (good, moderate and poor) with $96 \%$ accuracy. In another report using oligonucleotide microarrays to define ratios of gene expression to evaluate risk of recurrence in resected stage I adenocarcinomas (36 in the test set and 60 in the validation test), a three-ratio test predicting recurrence with $>90 \%$ accuracy was found [174]. Moreover, gene expression microarrays performed on 89 early-stage NSCLC identified profiles predicting recurrence after surgical resection better than the clinical predictor factors [80]. When applied to two independent cohorts of 25 and 84 early-stage NSCLC, the prediction accuracy was $72 \%$ and $79 \%$, respectively. A subgroup of stage IA patients at high risk for recurrence was also identified, which is useful as these patients are probably those who might best benefit from adjuvant chemotherapy. Meta-analyses also identified predictive markers $[169,175]$. In a cross-study comparison, gene expression profiles correlated to prognosis were poorly reproducible, altough 14 genes accurately predicted survival in the three studies being compared [169].

Recently, a pooled analysis of 442 lung adenocarcinomas from multiple institutions established the performance of gene expression signatures across different patient populations and different laboratories, which is necessary before considering any clinical application [176]. Investigators analysed whether gene expression data either alone or combined with clinical data could be used to predict overall survival in patients with lung cancer; several models were tested. When using gene expression data alone, only two models (out of eight) performed with consistent statistical significance and gave hazard ratios $(\mathrm{HR})>1$ for all pathological stages in the two validation datasets. When combining clinical and gene expression data the outcome prediction was improved, with HR $>2$ in two models. This study identified predictors of survival based on clinical and gene expression microarray data, with a better accuracy to predict survival when combining clinical and molecular data.

Proteomic studies have also been used to identify prognostic markers [171, 177]. In the most recent study [177], MALDI-MS was used to analyse protein profiles of surgically resected NSCLC. In the training set (116 NSCLC and 20 controls), a 25signal signature differentially expressed between patients with high and low risk of recurrence was found, associated with both relapse-free and overall survival. In the independent validation set (58 NSCLC and seven controls), the signature was also significantly associated with overall survival and, among patients with stage I disease only, to relapse-free survival. By predicting more accurately than the prognostic factors currently used (e.g. histology, and tumour, node, metatasis (TNM) classification), this signature indicates which patients are likely to relapse after surgery, and may help to decide when systemic adjuvant therapy will be beneficial. Recently, protein members of a candidate signature of prognosis previously identified by MALDI-MS were validated by immunohistochemistry (IHC) on lung cancer TMAs [178]. Combined IHC scores of calmodulin, thymosin $\beta 4$ and thymosin $\beta 10$ were correlated to survival. This combined strategy consisting of identification by MALDI-MS followed by validation by IHC represents key steps prior to bringing such candidates to the test in the clinical setting.

\section{Prediction of response to therapy}

The overall response to chemotherapy in NSCLC is $<30 \%$. Therefore, tremendous efforts are made to find biological markers that could identify patients who will actually benefit from a specific treatment and not suffer from its side-effects. Such markers could help to identify the best therapeutic strategies.

In a study using oligonucleotide microarrays to analyse 16 NSCLC specimens (eight in a training set and eight in a validation set), lysosomal protease inhibitors Serpin B3 and Cystatin $C$ predicted clinical response to platinum-based chemotherapy with $72 \%$ accuracy [179]. Another group compared microarray data to in vitro drug sensitivity data of various cancer cell lines and found gene expression profiles predicting sensitivity to individual chemotherapeutic drugs (topotecan, adriamycin, etoposide, 5-fluorouracil, paclitaxel, cyclophosphamide), validated in an independent set with $>80 \%$ accuracy [180]. Using published datasets, investigators showed that the in vitro-generated profiles were able to predict clinical response to individual drugs with $>81 \%$ accuracy, and also to multidrug regimens. In lung cancer cases, docetaxelsensitive individuals were likely to be resistant to etoposide. Investigators also linked gene expression signatures of chemotherapy sensitivity to those of known oncogenic pathways and found a significant association between PI3-kinase pathway deregulation and docetaxel resistance, suggesting a potential benefit to use PI3-kinase inhibitors in this subgroup (fig. 5).

To identify NSCLC patients likely to benefit from EGFR tyrosine kinase inhibitors (TKI) treatment, MALDI-MS was performed on pre-treatment sera of 302 patients treated with gefitinib or erlotinib (139 patients from three cohorts assigned into a training and 163 from two cohorts assigned into a validation set), as well as sera from 158 patients not treated with EGFR TKI [181]. An algorithm based on eight MS signals successfully identified patients with improved survival and time to progression after EGFR TKI treatment, independently of clinical factors associated with sensitivity to EGFR TKI (fig. 6). The algorithm did not accurately classify outcome of patients not treated with EGFR TKI.

Several studies found markers predicting response to therapy. However, for all of them, prospective validation studies are required to confirm their utility in the clinical setting.

\section{CONCLUSIONS AND FUTURE PERSPECTIVES}

This review highlights the impact of new global molecular approaches on our understanding of lung cancer biology and on the personalised management of patients with lung cancer. The studies presented here illustrate how the "-omics" era has revolutionised our approach to cancer biology. Genomics has been pioneering and has provided a solid base to our knowledge. Most importantly, genomics has led to discoveries with clinical implications. Even though genomics is still leading the field, there are growing interests in epigenetics and proteomics. Recently, the dynamics of proteins in response to anti-cancer 
a)

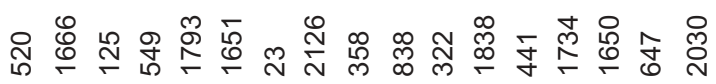

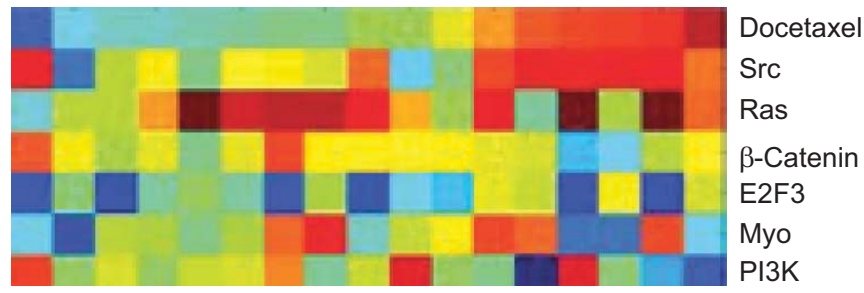

b)
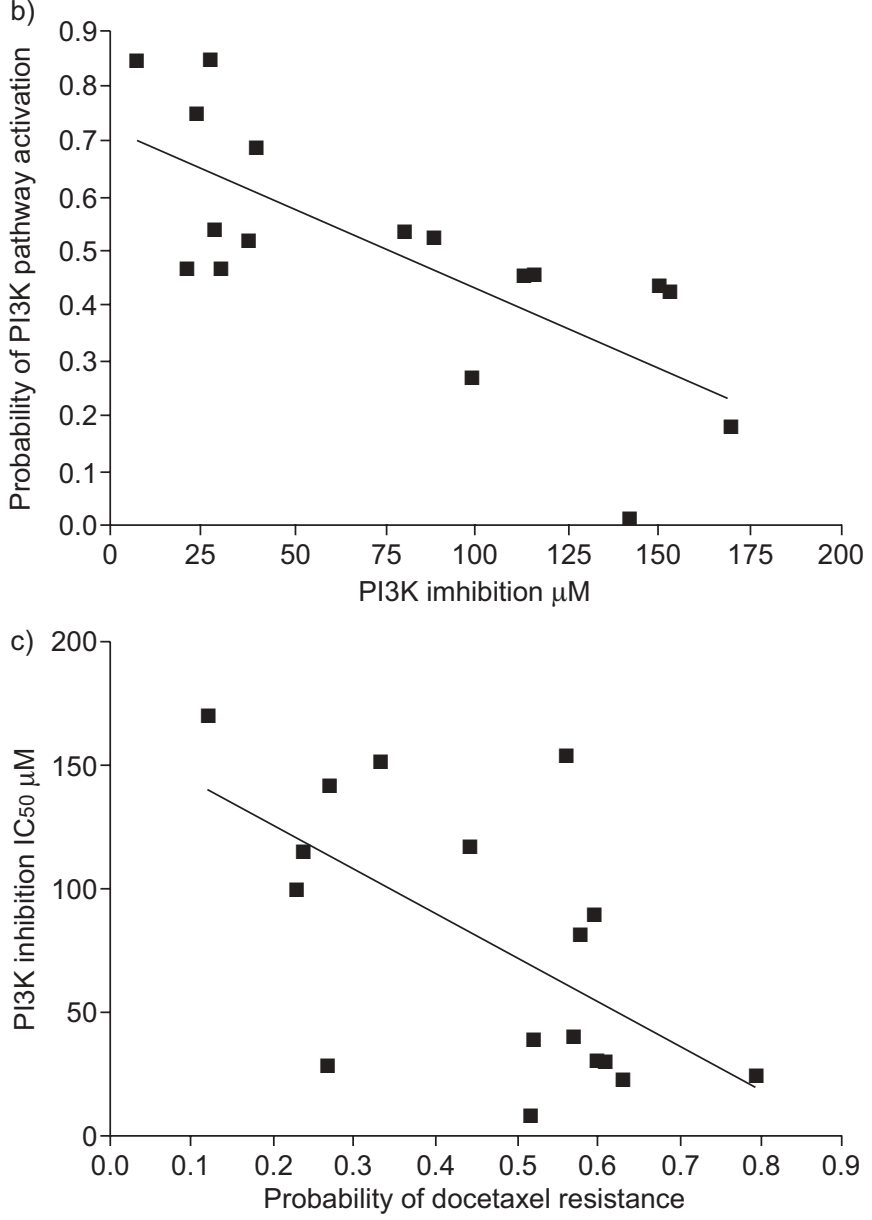

FIGURE 5. Relationship between predicted chemotherapeutic sensitivity and oncogenic pathway deregulation. a) Probability of oncogenic pathway deregulation as a function of predicted docetaxel sensitivity in a series of lung cancer cell lines (red: sensitive; blue: resistant). b) Lung cancer cell lines showing an increased probability of phosphoinositide 3-kinase (PI3K) activation were more likely to respond to a PI3K inhibitor ( $p=0.001$, log-rank test), as measured by sensitivity to the drug in cell proliferation assays. c) Furthermore, cell lines predicted to be resistant to docetaxel were more likely to be sensitive to PI3K inhibition $(p<0.001$. log-rank test). Src: avian sarcoma (Schmidt-Ruppin A-2) viral oncogene homologue; Ras: rat sarcoma viral oncogene homologue; E2F3: E2F transcription factor 3; Myc: myelocytomatosis viral oncogene homologue; IC50: half maximal inhibitory concentration. Reproduced from [180], with permission from the publisher.

drugs have been shown to differ between cancer cells according to their outcome (either cell death or survival), highlighting the importance of proteomics to help us understand the individual

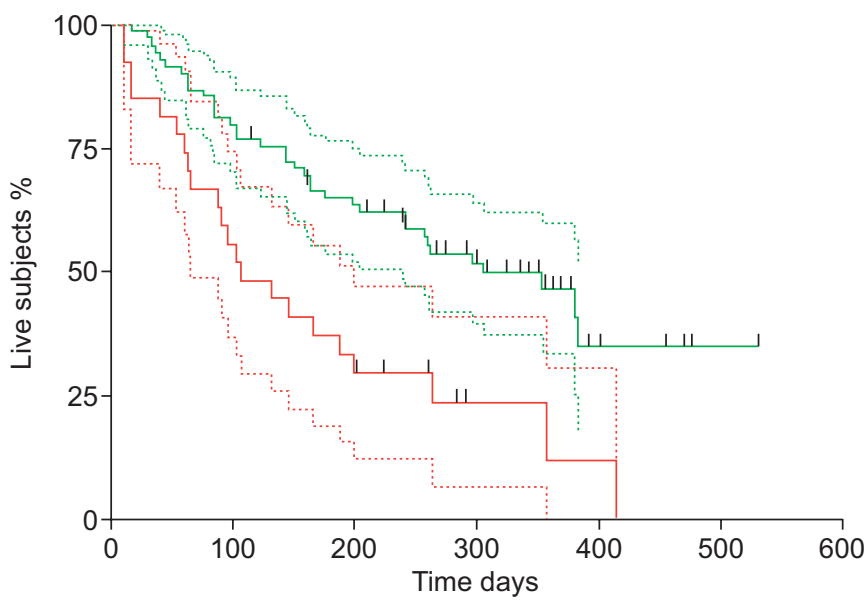

Number of patients at risk:

$\begin{array}{lccccccccc}\text { Time days } & 0 & 50 & 100 & 150 & 200 & 250 & 300 & 350 & 400 \\ \text { Good } & 69 & 64 & 56 & 51 & 43 & 37 & 26 & 18 & 6 \\ \text { Poor } & 27 & 22 & 16 & 12 & 8 & 7 & 3 & 3 & 2\end{array}$

FIGURE 6. Kaplan-Meier analysis of overall survival in the Eastern Cooperative Oncology Group validation cohort $(n=96)$. These patients had advanced nonsmall cell lung cancer and had been treated first line with erlotinib alone. red; poor eventfree fraction; green: good event-free fraction; ------: 95\% confidence intervals; |: censored patients. Reproduced from [181], with permission from the publisher.

molecular responses to drugs [182]. Early fields of glycomics and lipidomics also hold promise to improve our understanding of lung cancer biology.

However, multiple challenges lie ahead. While these highthroughput technologies hold the promise of bringing personalised lung cancer care to the clinic, the field is in need of careful validation of candidate biomarkers emerging from large discovery strategies. The integration of these highly dimensional and complex data will require major efforts in bioinformatics and biostatistics. It will take time before models showing how complementary these techniques are, are put to the test. Another major challenge is to study disease process rather than disease state and to do so in a high-throughput manner. We need to refine our methods of approaching the dynamics of the carcinogenic process. From the biomarker point of view, repetitive measurements of biomarkers in cohorts at risk will be critical in the future. For example, the identification of plasma DNA [183], circulating tumour antigens or their related auto-antibodies [184, 185] provides attractive means for early cancer diagnosis as well as a lead for therapy. A test based on the demonstration of auto-antibodies to tumour antigens in the sera of patients could be of great importance for early detection of cancer, since antibodies against a carcinogen stimulus could be detected well before the tumour phenotype arises. The future of a new area of investigation such as metabolomics rests with its ability to monitor subtle changes in the metabolome that occur prior to the detection of a gross phenotypic change reflecting disease. The integrated analysis of the "-omics" may provide more sensitive ways to detect changes related to the disease process and discover useful novel biomarkers. 


\section{SUPPORT STATEMENT}

This work was supported by National Institutes of Health grant CA102353, Lung SPORE CA90949, the Damon Runyon Cancer Research Foundation (New York, NY, USA; Ci no. 19-03), and a Merit Review grant from the US Department of Veterans Affairs to P.P. Massion. S. Ocak was supported by a grant from the Université Catholique de Louvain (Belgium) and an IASLC Lung Cancer Fellowship Award.

\section{STATEMENT OF INTEREST}

A statement of interest for R.K. Thomas can be found at www.erj. ersjournals.com $/ \mathrm{misc} /$ statements.dtl

\section{REFERENCES}

1 Parkin DM, Bray F, Ferlay J, et al. Global cancer statistics, 2002. CA Cancer J Clin 2005; 55: 74-108.

2 Giaccone G. Clinical impact of novel treatment strategies. Oncogene 2002; 21: 6970-6981.

3 Winton T, Livingston R, Johnson D, et al. Vinorelbine plus cisplatin vs. observation in resected non-small-cell lung cancer. N Engl J Med 2005; 352: 2589-2597.

4 Pisters KM, Le Chevalier T. Adjuvant chemotherapy in completely resected non-small-cell lung cancer. J Clin Oncol 2005; 23: 3270-3278.

5 Chanin TD, Merrick DT, Franklin WA, et al. Recent developments in biomarkers for the early detection of lung cancer: perspectives based on publications 2003 to present. Curr Opin Pulm Med 2004; 10: 242-247.

6 Chen G, Gharib TG, Huang CC, et al. Proteomic analysis of lung adenocarcinoma: identification of a highly expressed set of proteins in tumors. Clin Cancer Res 2002; 8: 2298-2305.

7 Wheeler DA, Srinivasan M, Egholm M, et al. The complete genome of an individual by massively parallel DNA sequencing. Nature 2008; 452: 872-876.

8 Wang J, Wang W, Li R, et al. The diploid genome sequence of an Asian individual. Nature 2008; 456: 60-65.

9 Levy S, Sutton G, Ng PC, et al. The diploid genome sequence of an individual human. PLoS Biol 2007; 5: e254.

10 Pinkel D, Segraves R, Sudar D, et al. High resolution analysis of DNA copy number variation using comparative genomic hybridization to microarrays. Nat Genet 1998; 20: 207-211.

11 Pollack JR, Perou CM, Alizadeh AA, et al. Genome-wide analysis of DNA copy-number changes using cDNA microarrays. Nat Genet 1999; 23: 41-46.

12 Ishkanian AS, Malloff CA, Watson SK, et al. A tiling resolution DNA microarray with complete coverage of the human genome. Nat Genet 2004; 36: 299-303.

13 Janne PA, Li C, Zhao X, et al. High-resolution single-nucleotide polymorphism array and clustering analysis of loss of heterozygosity in human lung cancer cell lines. Oncogene 2004; 23: 2716-2726.

14 Lindblad-Toh K, Tanenbaum DM, Daly MJ, et al. Loss-ofheterozygosity analysis of small-cell lung carcinomas using single-nucleotide polymorphism arrays. Nat Biotechnol 2000; 18: 1001-1005

15 Adorjan P, Distler J, Lipscher E, et al. Tumour class prediction and discovery by microarray-based DNA methylation analysis. Nucleic Acids Res 2002; 30: e21.

16 Yan PS, Wei SH, Huang TH. Methylation-specific oligonucleotide microarray. Methods Mol Biol 2004; 287: 251-260.

17 Ren B, Robert F, Wyrick JJ, et al. Genome-wide location and function of DNA binding proteins. Science 2000; 290: 2306-2309.

18 Schena M, Shalon D, Davis RW, et al. Quantitative monitoring of gene expression patterns with a complementary DNA microarray. Science 1995; 270: 467-470.
19 Golub TR, Slonim DK, Tamayo P, et al. Molecular classification of cancer: class discovery and class prediction by gene expression monitoring. Science 1999; 286: 531-537.

20 Liu CG, Calin GA, Meloon B, et al. An oligonucleotide microchip for genome-wide microRNA profiling in human and mouse tissues. Proc Natl Acad Sci USA 2004; 101: 9740-9744.

21 Bergman AC, Benjamin T, Alaiya A, et al. Identification of gelseparated tumor marker proteins by mass spectrometry. Electrophoresis 2000; 21: 679-686.

22 Patton WF. Detection technologies in proteome analysis J Chromatogr B Analyt Technol Biomed Life Sci 2002; 771: 3-31.

23 Caprioli RM, Farmer TB, Gile J. Molecular imaging of biological samples: localization of peptides and proteins using MALDITOF MS. Anal Chem 1997; 69: 4751-4760.

24 Farmer TB, Caprioli RM. Assessing the multimeric states of proteins: studies using laser desorption mass spectrometry. Biol Mass Spectrom 1991; 20: 796-800.

25 McCormack AL, Schieltz DM, Goode B, et al. Direct analysis and identification of proteins in mixtures by LC/MS/MS and database searching at the low-femtomole level. Anal Chem 1997; 69: 767-776.

26 Link AJ, Eng J, Schieltz DM, et al. Direct analysis of protein complexes using mass spectrometry. Nat Biotechnol 1999; 17: 676-682.

27 Wolters DA, Washburn MP, Yates JR 3rd. An automated multidimensional protein identification technology for shotgun proteomics. Anal Chem 2001; 73: 5683-5690.

28 Washburn MP, Wolters D, Yates JR. Large-scale analysis of the yeast proteome by multidimensional protein identification technology. Nat Biotechnol 2001; 19: 242-247.

29 Cargile BJ, Bundy JL, Stephenson JL Jr. Potential for false positive identifications from large databases through tandem mass spectrometry. J Proteome Res 2004; 3: 1082-1085.

30 Essader AS, Cargile BJ, Bundy JL, et al. A comparison of immobilized $\mathrm{pH}$ gradient isoelectric focusing and strong-cationexchange chromatography as a first dimension in shotgun proteomics. Proteomics 2005; 5: 24-34.

31 Liebler DC. Shotgun mass spec goes independent. Nat Methods 2004; 1: 16-17.

32 Liotta LA, Espina V, Mehta AI, et al. Protein microarrays: meeting analytical challenges for clinical applications. Cancer Cell 2003; 3: 317-325.

33 Wulfkuhle JD, Aquino JA, Calvert VS, et al. Signal pathway profiling of ovarian cancer from human tissue specimens using reverse-phase protein microarrays. Proteomics 2003; 3: 2085-2090.

34 Huang J, Zhu H, Haggarty SJ, et al. Finding new components of the target of rapamycin (TOR) signaling network through chemical genetics and proteome chips. Proc Natl Acad Sci USA 2004; 101: 16594-16599.

35 Kononen J, Bubendorf L, Kallioniemi A, et al. Tissue microarrays for high-throughput molecular profiling of tumor specimens. Nat Med 1998; 4: 844-847.

36 Shen J, Behrens C, Wistuba II, et al. Identification and validation of differences in protein levels in normal, premalignant, and malignant lung cells and tissues using high-throughput Western Array and immunohistochemistry. Cancer Res 2006; 66: 1119411206.

37 Morente MM, Mager R, Alonso S, et al. TuBaFrost 2: standardising tissue collection and quality control procedures for a European virtual frozen tissue bank network. Eur J Cancer 2006; 42: 2684-2691.

38 Orr S, Alexandre E, Clark B, et al. The establishment of a network of European human research tissue banks. Cell Tissue Bank 2002; 3: 133-137.

39 Blow N. Tissue preparation: tissue issues. Nature 2007; 448: 959-963.

40 Davies H, Bignell GR, Cox C, et al. Mutations of the BRAF gene in human cancer. Nature 2002; 417: 949-954. 
41 Naoki K, Chen TH, Richards WG, et al. Missense mutations of the BRAF gene in human lung adenocarcinoma. Cancer Res 2002; 62: 7001-7003.

42 Adjei AA, Cohen RB, Franklin W, et al. Phase I pharmacokinetic and pharmacodynamic study of the oral, small-molecule mitogen-activated protein kinase kinase 1/2 inhibitor AZD6244 (ARRY-142886) in patients with advanced cancers. J Clin Oncol 2008; 26: 2139-2146.

43 Samuels Y, Wang Z, Bardelli A, et al. High frequency of mutations of the PIK3CA gene in human cancers. Science 2004; 304: 554.

44 Kang S, Bader AG, Vogt PK. Phosphatidylinositol 3-kinase mutations identified in human cancer are oncogenic. Proc Natl Acad Sci USA 2005; 102: 802-807.

45 Serra V, Markman B, Scaltriti M, et al. NVP-BEZ235, a dual $\mathrm{PI} 3 \mathrm{~K} / \mathrm{mTOR}$ inhibitor, prevents PI3K signaling and inhibits the growth of cancer cells with activating PI3K mutations. Cancer Res 2008; 68: 8022-8030.

46 Lynch TJ, Bell DW, Sordella R, et al. Activating mutations in the epidermal growth factor receptor underlying responsiveness of non-small-cell lung cancer to gefitinib. N Engl J Med 2004; 350: 2129-2139.

47 Paez JG, Janne PA, Lee JC, et al. EGFR mutations in lung cancer: correlation with clinical response to gefitinib therapy. Science 2004; 304: 1497-1500.

48 Pao W, Miller V, Zakowski M, et al. EGF receptor gene mutations are common in lung cancers from "never smokers" and are associated with sensitivity of tumors to gefitinib and erlotinib. Proc Natl Acad Sci USA 2004; 101: 13306-13311.

49 Sharma SV, Bell DW, Settleman J, et al. Epidermal growth factor receptor mutations in lung cancer. Nat Rev Cancer 2007; 7: 169-181.

50 Carter TA, Wodicka LM, Shah NP, et al. Inhibition of drugresistant mutants of ABL, KIT, and EGF receptor kinases. Proc Natl Acad Sci USA 2005; 102: 11011-11016.

51 Kobayashi S, Boggon TJ, Dayaram T, et al. EGFR mutation and resistance of non-small-cell lung cancer to gefitinib. N Engl J Med 2005; 352: 786-792

52 Pao W, Miller VA, Politi KA, et al. Acquired resistance of lung adenocarcinomas to gefitinib or erlotinib is associated with a second mutation in the EGFR kinase domain. PLoS Med 2005; 2 e73.

53 Bean J, Brennan C, Shih JY, et al. MET amplification occurs with or without T790M mutations in EGFR mutant lung tumors with acquired resistance to gefitinib or erlotinib. Proc Natl Acad Sci USA 2007; 104: 20932-20937.

54 Engelman JA, Zejnullahu K, Mitsudomi T, et al. MET amplification leads to gefitinib resistance in lung cancer by activating ERBB3 signaling. Science 2007; 316: 1039-1043.

55 Cappuzzo F, Ligorio C, Janne PA, et al. Prospective study of gefitinib in epidermal growth factor receptor fluorescence in situ hybridization-positive/phospho-Akt-positive or never smoker patients with advanced non-small-cell lung cancer: the ONCOBELL trial. J Clin Oncol 2007; 25: 2248-2255.

56 Paz-Ares L JMS, Garcia-Velasco A, Massuti B, et al. A prospective phase II trial of erlotinib in advanced non-small cell lung cancer (NSCLC) patients (p) with mutations in the tyrosine kinase (TK) domain of the epidermal growth factor receptor (EGFR). J Clin Oncol 2006 ASCO Annual Meeting Proceedings Part I 2006; 24: 18 S.

57 Sequist LV, Martins RG, Spigel D, et al. First-line gefitinib in patients with advanced non-small-cell lung cancer harboring somatic EGFR mutations. J Clin Oncol 2008; 26: 2442-2449.

58 Sugio UH, Oyama T, Onizuka T, et al. A prospective phase II study of gefitinib in non-small cell lung cancer patients with epidermal growth factor receptor gene (EGFR) mutations. J Clin Oncol 2006 ASCO Annual Meeting Proceedings Part I 2007; 25: 18 S.
59 Yamamoto $\mathrm{H}$, Toyooka S, Mitsudomi T. Impact of EGFR mutation analysis in non-small cell lung cancer. Lung Cancer 2009; 63: 315-321.

60 Eberhard DA, Johnson BE, Amler LC, et al. Mutations in the epidermal growth factor receptor and in KRAS are predictive and prognostic indicators in patients with non-small-cell lung cancer treated with chemotherapy alone and in combination with erlotinib. J Clin Oncol 2005; 23: 5900-5909.

61 Douillard HV, Mok TS, Socinski A, et al. Molecular and clinical subgroup analyses from a phase III trial comparing gefitinib with docetaxel in previously treated non-small cell lung cancer (INTEREST). J Clin Oncol 2008 ASCO Annual Meeting Proceedings (post-meeting edition) 2008; 26: Suppl., abstract 8001

62 Mok T, Wu Y-L, Thongprasert S et al. Phase III, randomized, open-label, first line study of gefitinib vs carboplatin/paclitaxel in clinically selected patients with advanced non-small-cell lung cancer (NSCLC) (IPASS) [abstract LBA2]. Ann Oncol 2008; 19: Suppl. 8, VIII1.

63 Eberhard DA, Giaccone G, Johnson BE. Biomarkers of response to epidermal growth factor receptor inhibitors in Non-Small-Cell Lung Cancer Working Group: standardization for use in the clinical trial setting. J Clin Oncol 2008; 26: 983-994.

64 Hirsch FR, Varella-Garcia M, McCoy J, et al. Increased epidermal growth factor receptor gene copy number detected by fluorescence in situ hybridization associates with increased sensitivity to gefitinib in patients with bronchioloalveolar carcinoma subtypes: a Southwest Oncology Group Study. J Clin Oncol 2005; 23: 6838-6845.

65 Tsao MS, Sakurada A, Cutz JC, et al. Erlotinib in lung cancer: molecular and clinical predictors of outcome. N Engl J Med 2005; 353: 133-144.

66 Yatabe Y, Takahashi T, Mitsudomi T. Epidermal growth factor receptor gene amplification is acquired in association with tumor progression of EGFR-mutated lung cancer. Cancer Res 2008; 68: 2106-2111.

67 Sanger F, Nicklen S, Coulson AR. DNA sequencing with chainterminating inhibitors. Proc Natl Acad Sci USA 1977; 74: 54635467.

68 Thomas RK, Nickerson E, Simons JF, et al. Sensitive mutation detection in heterogeneous cancer specimens by massively parallel picoliter reactor sequencing. Nat Med 2006; 12: 852-855.

69 Thomas RK, Baker AC, Debiasi RM, et al. High-throughput oncogene mutation profiling in human cancer. Nat Genet 2007; 39: $347-351$

70 Campbell PJ, Stephens PJ, Pleasance ED, et al. Identification of somatically acquired rearrangements in cancer using genomewide massively parallel paired-end sequencing. Nat Genet 2008; 40: 722-729.

71 Jones S, Zhang X, Parsons DW, et al. Core signaling pathways in human pancreatic cancers revealed by global genomic analyses. Science 2008; 321: 1801-1806.

72 McLendon R, Friedman A, Bigner D, et al. Comprehensive genomic characterization defines human glioblastoma genes and core pathways. Nature 2008; 455: 1061-1068.

73 Parsons DW, Jones S, Zhang X, et al. An integrated genomic analysis of human glioblastoma multiforme. Science 2008; 321: 1807-1812.

74 Wood LD, Parsons DW, Jones S, et al. The genomic landscapes of human breast and colorectal cancers. Science 2007; 318: 11081113.

75 Beer DG, Kardia SL, Huang CC, et al. Gene-expression profiles predict survival of patients with lung adenocarcinoma. Nat Med 2002; 8: 816-824.

76 Bhattacharjee A, Richards WG, Staunton J, et al. Classification of human lung carcinomas by mRNA expression profiling reveals distinct adenocarcinoma subclasses. Proc Natl Acad Sci USA 2001; 98: 13790-13795. 
77 Hayes DN, Monti S, Parmigiani G, et al. Gene expression profiling reveals reproducible human lung adenocarcinoma subtypes in multiple independent patient cohorts. J Clin Oncol 2006; 24: 5079-5090.

$78 \mathrm{Lu} \mathrm{Y,} \mathrm{Lemon} \mathrm{W,} \mathrm{Liu} \mathrm{PY,} \mathrm{et} \mathrm{al.} \mathrm{A} \mathrm{gene} \mathrm{expression} \mathrm{signature}$ predicts survival of patients with stage I non-small cell lung cancer. PLoS Med 2006; 3: e467.

79 Xi L, Lyons-Weiler J, Coello MC, et al. Prediction of lymph node metastasis by analysis of gene expression profiles in primary lung adenocarcinomas. Clin Cancer Res 2005; 11: 4128-4135.

80 Potti A, Mukherjee S, Petersen R, et al. A genomic strategy to refine prognosis in early-stage non-small-cell lung cancer. $N$ Engl J Med 2006; 355: 570-580.

81 Gray JW, Collins C. Genome changes and gene expression in human solid tumors. Carcinogenesis 2000; 21: 443-452.

82 Futreal PA, Coin L, Marshall M, et al. A census of human cancer genes. Nat Rev Cancer 2004; 4: 177-183.

83 Garnis C, Lockwood WW, Vucic E, et al. High resolution analysis of non-small cell lung cancer cell lines by whole genome tiling path array CGH. Int J Cancer 2006; 118: 1556-1564.

84 Massion PP, Kuo WL, Stokoe D, et al. Genomic copy number analysis of non-small cell lung cancer using array comparative genomic hybridization: implications of the phosphatidylinositol 3-kinase pathway. Cancer Res 2002; 62: 3636-3640.

85 Tonon G, Wong KK, Maulik G, et al. High-resolution genomic profiles of human lung cancer. Proc Natl Acad Sci USA 2005; 102: 9625-9630.

86 Dehan E, Ben-Dor A, Liao W, et al. Chromosomal aberrations and gene expression profiles in non-small cell lung cancer. Lung Cancer 2007; 56: 175-184.

87 Zhao X, Weir BA, LaFramboise T, et al. Homozygous deletions and chromosome amplifications in human lung carcinomas revealed by single nucleotide polymorphism array analysis. Cancer Res 2005; 65: 5561-5570.

88 Imoto I, Yuki Y, Sonoda I, et al. Identification of ZASC1 encoding a Kruppel-like zinc finger protein as a novel target for 3q26 amplification in esophageal squamous cell carcinomas. Cancer Res 2003; 63: 5691-5696.

89 Singh B, Gogineni SK, Sacks PG, et al. Molecular cytogenetic characterization of head and neck squamous cell carcinoma and refinement of 3q amplification. Cancer Res 2001; 61: 4506-4513.

90 Qian J, Massion PP. Role of chromosome 3q amplification in lung cancer. J Thorac Oncol 2008; 3: 212-215.

91 Levin NA, Brzoska PM, Warnock ML, et al. Identification of novel regions of altered DNA copy number in small cell lung tumors. Genes Chromosomes Cancer 1995; 13: 175-185.

92 Harvey BG, Heguy A, Leopold PL, et al. Modification of gene expression of the small airway epithelium in response to cigarette smoking. J Mol Med 2007; 85: 39-53.

93 Ammous Z, Hackett NR, Butler MW, et al. Variability in small airway epithelial gene expression among normal smokers. Chest 2008; 133: 1344-1353.

94 Hackett NR, Heguy A, Harvey BG, et al. Variability of antioxidant-related gene expression in the airway epithelium of cigarette smokers. Am J Respir Cell Mol Biol 2003; 29: 331-343.

95 Spira A, Beane J, Shah V, et al. Effects of cigarette smoke on the human airway epithelial cell transcriptome. Proc Natl Acad Sci USA 2004; 101: 10143-10148.

96 Spira A, Beane JE, Shah V, et al. Airway epithelial gene expression in the diagnostic evaluation of smokers with suspect lung cancer. Nat Med 2007; 13: 361-366.

97 Beane J, Sebastiani P, Whitfield TH, et al. A prediction model for lung cancer diagnosis that integrates genomic and clinical features. Cancer Prev Res 2008; 1: 56-64.

98 Huang E, Ishida S, Pittman J, et al. Gene expression phenotypic models that predict the activity of oncogenic pathways. Nat Genet 2003; 34: 226-230.
99 Black EP, Huang E, Dressman H, et al. Distinct gene expression phenotypes of cells lacking $\mathrm{Rb}$ and $\mathrm{Rb}$ family members. Cancer Res 2003; 63: 3716-3723.

100 Segal E, Friedman N, Koller D, et al. A module map showing conditional activity of expression modules in cancer. Nat Genet 2004; 36: 1090-1098.

101 Rhodes DR, Yu J, Shanker K, et al. Large-scale meta-analysis of cancer microarray data identifies common transcriptional profiles of neoplastic transformation and progression. Proc Natl Acad Sci USA 2004; 101: 9309-9314.

102 Ramaswamy S, Ross KN, Lander ES, et al. A molecular signature of metastasis in primary solid tumors. Nat Genet 2003; 33: 49-54.

103 Bild AH, Yao G, Chang JT, et al. Oncogenic pathway signatures in human cancers as a guide to targeted therapies. Nature 2006; 439: 353-357.

104 Esteller M, Fraga MF, Paz MF, et al. Cancer epigenetics and methylation. Science 2002; 297: 1807-1808.

105 Esteller M, Sanchez-Cespedes M, Rosell R, et al. Detection of aberrant promoter hypermethylation of tumor suppressor genes in serum DNA from non-small cell lung cancer patients. Cancer Res 1999; 59: 67-70.

106 Ahrendt SA, Chow JT, Xu LH, et al. Molecular detection of tumor cells in bronchoalveolar lavage fluid from patients with early stage lung cancer. J Natl Cancer Inst 1999; 91: 332-339.

107 Belinsky SA, Palmisano WA, Gilliland FD, et al. Aberrant promoter methylation in bronchial epithelium and sputum from current and former smokers. Cancer Res 2002; 62: 2370-2377.

$108 \mathrm{Ng} \mathrm{CS}$, Zhang J, Wan S, et al. Tumor p16M is a possible marker of advanced stage in non-small cell lung cancer. J Surg Oncol 2002; 79: 101-106.

109 Palmisano WA, Divine KK, Saccomanno G, et al. Predicting lung cancer by detecting aberrant promoter methylation in sputum. Cancer Res 2000; 60: 5954-5958.

110 Belinsky SA, Nikula KJ, Palmisano WA, et al. Aberrant methylation of p16(INK4a) is an early event in lung cancer and a potential biomarker for early diagnosis. Proc Natl Acad Sci USA 1998; 95: 11891-11896.

111 Nuovo GJ, Plaia TW, Belinsky SA, et al. In situ detection of the hypermethylation-induced inactivation of the p16 gene as an early event in oncogenesis. Proc Natl Acad Sci USA 1999; 96: 12754-12759.

112 Brock MV, Hooker CM, Ota-Machida E, et al. DNA methylation markers and early recurrence in stage I lung cancer. N Engl J Med 2008; 358: 1118-1128.

113 Zhong S, Fields CR, Su N, et al. Pharmacologic inhibition of epigenetic modifications, coupled with gene expression profiling, reveals novel targets of aberrant DNA methylation and histone deacetylation in lung cancer. Oncogene 2007; 26: 26212634.

114 Rauch TA, Zhong X, Wu X, et al. High-resolution mapping of DNA hypermethylation and hypomethylation in lung cancer. Proc Natl Acad Sci USA 2008; 105: 252-257.

115 Brena RM, Morrison C, Liyanarachchi S, et al. Aberrant DNA methylation of OLIG1, a novel prognostic factor in non-small cell lung cancer. PLoS Med 2007; 4: e108.

116 Brehm A, Miska EA, McCance DJ, et al. Retinoblastoma protein recruits histone deacetylase to repress transcription. Nature 1998; 391: 597-601.

117 Mukhopadhyay NK, Weisberg E, Gilchrist D, et al. Effectiveness of trichostatin A as a potential candidate for anticancer therapy in non-small-cell lung cancer. Ann Thorac Surg 2006; 81: 10341042.

118 Kim SM, Kee HJ, Eom GH, et al. Characterization of a novel WHSC1-associated SET domain protein with H3K4 and H3K27 methyltransferase activity. Biochem Biophys Res Commun 2006; 345: 318-323. 
119 Loprevite M, Tiseo M, Grossi F, et al. In vitro study of CI-994, a histone deacetylase inhibitor, in non-small cell lung cancer cell lines. Oncol Res 2005; 15: 39-48.

120 Ambros V. MicroRNA pathways in flies and worms: growth, death, fat, stress, and timing. Cell 2003; 113: 673-676.

121 Yanaihara N, Caplen N, Bowman E, et al. Unique microRNA molecular profiles in lung cancer diagnosis and prognosis. Cancer Cell 2006; 9: 189-198.

122 Takamizawa J, Konishi H, Yanagisawa K, et al. Reduced expression of the let-7 microRNAs in human lung cancers in association with shortened postoperative survival. Cancer Res 2004; 64: 3753-3756.

123 Rikova K, Guo A, Zeng Q, et al. Global survey of phosphotyrosine signaling identifies oncogenic kinases in lung cancer. Cell 2007; 131: 1190-1203.

124 Lopez-Ferrer A, Curull V, Barranco C, et al. Mucins as differentiation markers in bronchial epithelium. Squamous cell carcinoma and adenocarcinoma display similar expression patterns. Am J Respir Cell Mol Biol 2001; 24: 22-29.

125 Wagner KW, Punnoose EA, Januario T, et al. Death-receptor $O$ glycosylation controls tumor-cell sensitivity to the proapoptotic ligand Apo2L/TRAIL. Nat Med 2007; 13: 1070-1077.

126 Zhao YY, Takahashi M, Gu JG, et al. Functional roles of $N$ glycans in cell signaling and cell adhesion in cancer. Cancer Sci 2008; 99: 1304-1310.

127 Wang $\mathrm{X}, \mathrm{Gu} \mathrm{J}$, Ihara $\mathrm{H}$, et al. Core fucosylation regulates epidermal growth factor receptor-mediated intracellular signaling. J Biol Chem 2006; 281: 2572-2577.

128 Zhao J, Qiu W, Simeone DM, et al. N-linked glycosylation profiling of pancreatic cancer serum using capillary liquid phase separation coupled with mass spectrometric analysis. J Proteome Res 2007; 6: 1126-1138.

129 Hirabayashi J. Concept, strategy and realization of lectin-based glycan profiling. J Biochem 2008; 144: 139-147.

130 Allahverdian S, Patchell BJ, Dorscheid DR. Carbohydrates and epithelial repair-more than just post-translational modification. Curr Drug Targets 2006; 7: 597-606.

131 Handa K, Kojima N, Hakomori S. Analysis of glycolipiddependent cell adhesion based on carbohydrate-carbohydrate interaction. Methods Enzymol 2000; 312: 447-458.

132 Pettijohn DE, Pfenninger O, Brown J, et al. Tumorigenic human squamous lung cancer cells have defined cell surface carbohydrates that are absent from nontumorigenic cells. Proc Natl Acad Sci USA 1988; 85: 802-806.

133 Heo SH, Lee SJ, Ryoo HM, et al. Identification of putative serum glycoprotein biomarkers for human lung adenocarcinoma by multilectin affinity chromatography and LC-MS/MS. Proteomics 2007; 7: 4292-4302.

134 Bruno R, Olivares R, Berille J, et al. Alpha-1-acid glycoprotein as an independent predictor for treatment effects and a prognostic factor of survival in patients with non-small cell lung cancer treated with docetaxel. Clin Cancer Res 2003; 9: 1077-1082.

135 Fujiwara Y, Kiura K, Toyooka S, et al. Elevated serum level of sialylated glycoprotein KL-6 predicts a poor prognosis in patients with non-small cell lung cancer treated with gefitinib. Lung Cancer 2008; 59: 81-87.

136 Hakomori S. Tumor-associated carbohydrate antigens defining tumor malignancy: basis for development of anti-cancer vaccines. Adv Exp Med Biol 2001; 491: 369-402.

137 Wenk MR. The emerging field of lipidomics. Nat Rev Drug Discov 2005; 4: 594-610.

138 Serrano AG, Perez-Gil J. Protein-lipid interactions and surface activity in the pulmonary surfactant system. Chem Phys Lipids 2006; 141: 105-118.

139 Keith RL, Geraci MW. Prostacyclin in lung cancer. J Thorac Oncol 2006; 1: 503-505.
140 Kong D, Yamori T. Phosphatidylinositol 3-kinase inhibitors: promising drug candidates for cancer therapy. Cancer Sci 2008; 99: 1734-1740.

141 Orita $\mathrm{H}$, Coulter J, Lemmon $\mathrm{C}$, et al. Selective inhibition of fatty acid synthase for lung cancer treatment. Clin Cancer Res 2007; 13 7139-7145.

142 Peto R, Darby S, Deo H, et al. Smoking, smoking cessation, and lung cancer in the UK since 1950: combination of national statistics with two case-control studies. BMJ 2000; 321: 323-329.

143 Mattson ME, Pollack ES, Cullen JW. What are the odds that smoking will kill you? Am J Public Health 1987; 77: 425-431.

144 Tokuhata GK, Lilienfeld AM. Familial aggregation of lung cancer in humans. J Natl Cancer Inst 1963; 30: 289-312.

145 Bailey-Wilson JE, Amos CI, Pinney SM, et al. A major lung cancer susceptibility locus maps to chromosome 6q23-25. Am J Hum Genet 2004; 75: 460-474.

146 Smith LT, Lin M, Brena RM, et al. Epigenetic regulation of the tumor suppressor gene TCF21 on 6q23-q24 in lung and head and neck cancer. Proc Natl Acad Sci USA 2006; 103: 982-987.

147 Tessema M, Willink R, Do K, et al. Promoter methylation of genes in and around the candidate lung cancer susceptibility locus 6q23-25. Cancer Res 2008; 68: 1707-1714.

148 Ye Z, Song H, Higgins JP, et al. Five glutathione s-transferase gene variants in 23,452 cases of lung cancer and 30,397 controls: meta-analysis of 130 studies. PLoS Med 2006; 3: e91.

149 Manuguerra M, Saletta F, Karagas MR, et al. XRCC3 and XPD/ ERCC2 single nucleotide polymorphisms and the risk of cancer: a HuGE review. Am I Epidemiol 2006; 164: 297-302.

150 Hung RJ, Hall J, Brennan P, et al. Genetic polymorphisms in the base excision repair pathway and cancer risk: a HuGE review. Am J Epidemiol 2005; 162: 925-942.

151 Campa D, Zienolddiny S, Lind $\mathrm{H}$, et al. Polymorphisms of dopamine receptor/transporter genes and risk of non-small cell lung cancer. Lung Cancer 2007; 56: 17-23.

152 Amos CI, Wu X, Broderick P, et al. Genome-wide association scan of tag SNPs identifies a susceptibility locus for lung cancer at 15q25.1. Nat Genet 2008; 40: 616-622.

153 Minna JD. Nicotine exposure and bronchial epithelial cell nicotinic acetylcholine receptor expression in the pathogenesis of lung cancer. J Clin Invest 2003; 111: 31-33.

154 Lam DC, Girard L, Ramirez R, et al. Expression of nicotinic acetylcholine receptor subunit genes in non-small-cell lung cancer reveals differences between smokers and nonsmokers. Cancer Res 2007; 67: 4638-4647.

155 Zhang Q, Tang X, Zhang ZF, et al. Nicotine induces hypoxiainducible factor-1alpha expression in human lung cancer cells via nicotinic acetylcholine receptor-mediated signaling pathways. Clin Cancer Res 2007; 13: 4686-4694.

156 Hung RJ, McKay JD, Gaborieau V, et al. A susceptibility locus for lung cancer maps to nicotinic acetylcholine receptor subunit genes on 15q25. Nature 2008; 452: 633-637.

157 Thorgeirsson TE, Geller F, Sulem P, et al. A variant associated with nicotine dependence, lung cancer and peripheral arterial disease. Nature 2008; 452: 638-642.

158 Seemann MD, Beinert $\mathrm{T}$, Furst $\mathrm{H}$, et al. An evaluation of the tumour markers, carcinoembryonic antigen (CEA), cytokeratin marker (CYFRA 21-1) and neuron-specific enolase (NSE) in the differentiation of malignant from benign solitary pulmonary lesions. Lung Cancer 1999; 26: 149-155.

159 Pastor A, Menendez R, Cremades MJ, et al. Diagnostic value of SCC, CEA and CYFRA 21.1 in lung cancer: a Bayesian analysis. Eur Respir J 1997; 10: 603-609.

160 Kulpa J, Wojcik E, Reinfuss M, et al. Carcinoembryonic antigen, squamous cell carcinoma antigen, CYFRA 21-1, and neuronspecific enolase in squamous cell lung cancer patients. Clin Chem 2002; 48: 1931-1937. 
161 Patz EF Jr, Campa MJ, Gottlin EB, et al. Panel of serum biomarkers for the diagnosis of lung cancer. J Clin Oncol 2007; 25: 5578-5583.

162 Yildiz PB, Shyr Y, Rahman JS, et al. Diagnostic accuracy of MALDI mass spectrometric analysis of unfractionated serum in lung cancer. J Thorac Oncol 2007; 2: 893-901.

163 Fujii T, Dracheva T, Player A, et al. A preliminary transcriptome map of non-small cell lung cancer. Cancer Res 2002; 62: 33403346.

164 Garber ME, Troyanskaya OG, Schluens K, et al. Diversity of gene expression in adenocarcinoma of the lung. Proc Natl Acad Sci USA 2001; 98: 13784-13789.

165 Nacht M, Dracheva T, Gao Y, et al. Molecular characteristics of non-small cell lung cancer. Proc Natl Acad Sci USA 2001; 98: 15203-15208.

166 Sugita M, Geraci M, Gao B, et al. Combined use of oligonucleotide and tissue microarrays identifies cancer/testis antigens as biomarkers in lung carcinoma. Cancer Res 2002; 62: 3971-3979.

167 Raponi M, Zhang Y, Yu J, et al. Gene expression signatures for predicting prognosis of squamous cell and adenocarcinomas of the lung. Cancer Res 2006; 66: 7466-7472.

168 Borczuk AC, Gorenstein L, Walter KL, et al. Non-small-cell lung cancer molecular signatures recapitulate lung developmental pathways. Am J Pathol 2003; 163: 1949-1960.

169 Parmigiani G, Garrett-Mayer ES, Anbazhagan R, et al. A crossstudy comparison of gene expression studies for the molecular classification of lung cancer. Clin Cancer Res 2004; 10: 2922-2927.

170 Shyr Y, Kim K. Weighted flexible compound covariate method for classifying microarray data. In: Berrar D, ed. A Practical Approach to Microarray Data Analysis. New York, Kluwer Academic, 2003; pp. 186-200.

171 Yanagisawa K, Shyr Y, Xu BJ, et al. Proteomic patterns of tumour subsets in non-small-cell lung cancer. Lancet 2003; 362: 433-439.

172 Rahman SM, Shyr Y, Yildiz PB, et al. Proteomic patterns of preinvasive bronchial lesions. Am J Respir Crit Care Med 2005; 172: 1556-1562.

173 Guo L, Ma Y, Ward R, et al. Constructing molecular classifiers for the accurate prognosis of lung adenocarcinoma. Clin Cancer Res 2006; $12:$ 3344-3354.
174 Gordon GJ, Jensen RV, Hsiao LL, et al. Using gene expression ratios to predict outcome among patients with mesothelioma. J Natl Cancer Inst 2003; 95: 598-605.

175 Jiang H, Deng Y, Chen HS, et al. Joint analysis of two microarray gene-expression data sets to select lung adenocarcinoma marker genes. BMC Bioinformatics 2004; 5: 81.

176 Shedden K, Taylor JM, Enkemann SA, et al. Gene expressionbased survival prediction in lung adenocarcinoma: a multi-site, blinded validation study. Nat Med 2008; 14: 822-827.

177 Yanagisawa K, Tomida S, Shimada Y, et al. A 25-signal proteomic signature and outcome for patients with resected non-small-cell lung cancer. J Natl Cancer Inst 2007; 99: 858-867.

$178 \mathrm{Xu}$ BJ, Gonzalez AL, Kikuchi T, et al. MALDI-MS derived prognostic protein markers for resected non-small cell lung cancer. Proteomics ClinAppl 2008; 2: 1508-1517.

179 Petty RD, Kerr KM, Murray GI, et al. Tumor transcriptome reveals the predictive and prognostic impact of lysosomal protease inhibitors in non-small-cell lung cancer. J Clin Oncol 2006; 24: 1729-1744.

180 Potti A, Dressman HK, Bild A, et al. Genomic signatures to guide the use of chemotherapeutics. Nat Med 2006; 12: 1294-1300.

181 Taguchi F, Solomon B, Gregorc V, et al. Mass spectrometry to classify non-small-cell lung cancer patients for clinical outcome after treatment with epidermal growth factor receptor tyrosine kinase inhibitors: a multicohort cross-institutional study. J Natl Cancer Inst 2007; 99: 838-846.

182 Cohen AA, Geva-Zatorsky N, Eden E, et al. Dynamic proteomics of individual cancer cells in response to a drug. Science 2008; 322 1511-1516.

183 Sozzi G, Roz L, Conte D, et al. Plasma DNA quantification in lung cancer computed tomography screening: five-year results of a prospective study. Am J Respir Crit Care Med 2009; 179: 69-74.

184 Zhong L, Hidalgo GE, Stromberg AJ, et al. Using protein microarray as a diagnostic assay for non-small cell lung cancer. Am J Respir Crit Care Med 2005; 172: 1308-1314.

185 Zhong L, Peng X, Hidalgo GE, et al. Identification of circulating antibodies to tumor-associated proteins for combined use as markers of non-small cell lung cancer. Proteomics 2004; 4: $1216-1225$. 